\title{
Breaking new ground: challenges and opportunities for maximising value from underground blasting
}

\author{
EJ Sellers CSIRO, and Mining3, Australia \\ EF Salmi CSIRO, and Mining3, Australia
}

\begin{abstract}
The challenges of underground mining operations have discouraged mine-to-mill value optimisation to maximise metal production by tailoring fragmentation for plant throughput. Improved and automated blasting techniques are required for modern remote, deeper, and highly stressed operations. The definition of value is changing with investors seeking environmental, social, and governance measures, as well as the traditional revenue and net present value approaches. In this paper, analyses of blasting from a range of underground operations are used to highlight the current challenges. Demonstration of how the lack of sufficient and appropriate continuous, 3D measurement of important properties such as blastability, in situ structures, hole deviation, and fragmentation aligned with the limited insights into the effect of mining-induced stresses show how current approaches can often lead to overbreak, dilution, production delays, the lack of excavation stability, and poor plant performance. The real-time fusion of data to recalibrate and monitor the continuously changing environment is required. On the horizon, there is a suite of new technologies such as wireless detonators, nitrate-free explosives, robotic operations, and cognitive spatial management that will enable a new generation of mining methods. These include in-place operations and in-mine recovery where the material movement and the environmental footprint of mining operations is reduced whilst extraction is optimised, and productivity and excavation stability increased.
\end{abstract}

Keywords: blasting, geotechnical, rock mass, mine, value, optimisation, technology

\section{Introduction}

There are multiple underground mining methods (Hamrin 2001) with multiple blast design approaches (Holmberg et al. 2001). A selection of these methods and their blast design requirements (BDR) can be seen in Figure 1. The BDR classification scheme (Little \& Lovitt 2018) have a code for the blasting objectives, namely 1_2G_3F_4560, where the numerals are substituted by capital letters as follows: 1 for surface, underground or underwater, 2 can be single or multiple grades (ores), and 3 notes the face conditions and relationship with the blasthole directions. The technical objectives 4, 5, and 6 can be any one of grade control, ore control, fragmentation control, muck pile control, damage control, profile control, and environmental control, but repetition is not permitted. For further details on the approach, see Little \& Lovitt (2018). Since the technical details classify the most important design considerations, these also denote how the blast can create or destroy value within the mining operation.

Value addition in underground mining is conventionally considered to include the creation of net value, value-based ore control, and producing reliable, quality, blast outcomes (Little \& Lovitt 2018). What used to be considered good management prerequisites, e.g. worker safety, risk management, legal compliance, and consideration of natural or man-made site conditions, have now become vital opportunities for creating value for shareholders that associate environmental, social and governance (ESG) performance being considered by investors as much as financial measures such as net present value (NPV) (Little \& Lovitt 2018; Zhang 2008). Good ESG performance and disclosure are closely correlated to company performance (Fatemi et al. 2018). To add financial value, mine-to-mill optimisation (McKee 2013) has long been applied in open pit mining operations (Scott et al. 1999, 2002). Finer fragmentation due to additional blast energy leads to increased throughput and creates extra value from additional revenue by relieving constraints in the plant 
(Kanchibotla et al. 1998). Detailed comparisons of fragmentation modelling cannot be provided here and further information including comparisons with new approaches such as the distribution-free model for the prediction of fragmentation for mine-to-mill optimisation can be seen in the relevant literature (Ouchterlony \& Sanchidrián 2019; Sanchidrián et al. 2012, 2014).

The Theory of Constraints (TOC) proposed by Goldratt (1984) is a methodology for identifying the most important limiting factor (e.g. constraint) that stands in the way of achieving a goal. It then tries to systematically improve the constraint until it is no longer the limiting factor. In mining, the constraint is often referred to as a bottleneck, though technically a bottleneck is a temporary constraint. TOC can be considered an aspect of lean production. It assumes that every process has a single bottleneck or constraint and so throughput of the process can only be improved when the constraint is removed or the capacity increased. Additionally, the optimisation of processes that are not constraints may increase costs and occupy resources but will not provide additional value as only improvements to the constraint throughput will further the goal of additional profit. Therefore, operations downstream of blasting must be considered in the total value return to the mining operation and additional blast energy input may create extra cost, though added overall value by ensuring additional throughput (Kanchibotla et al. 1998). The improvement of fragmentation in mining may, however, be considered as an optimisation problem under multiple constraints. The design shall not only provide good fragmentation based on the needs of the downstream processes but must reduce the blast-induced damage and ground vibration that may cause geotechnical issues. Mine-to-mill optimisation should account for geotechnical stability, otherwise significant value can be lost (Etchells et al. 2013) and can be achieved by active splitting that prevents activation of large-scale geological features (Gaunt et al. 2015), as well as by altering the wall design and blasting practices (Sellers et al. 2018).

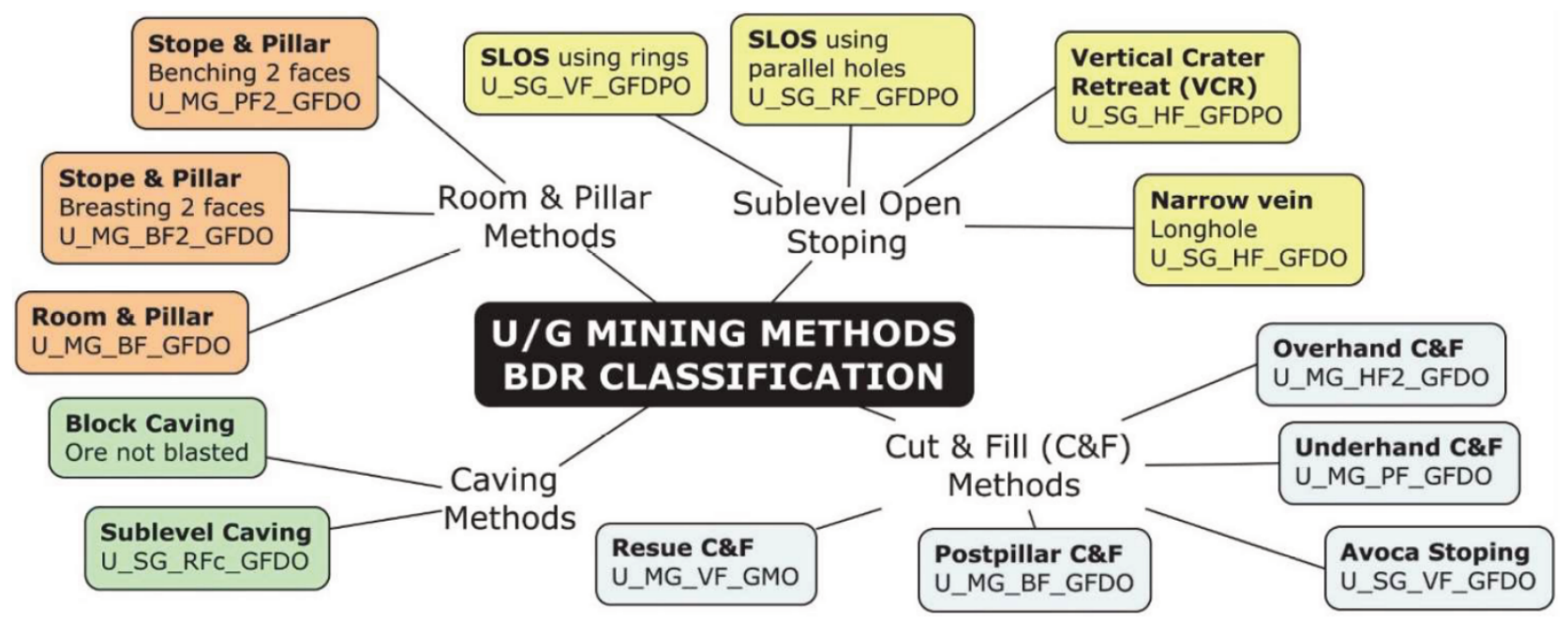

Figure 1 Underground mine design methods and their blast design requirements (BDR) (Little \& Lovitt 2018)

As shown in red in Figure 2, there are only a couple of processes in open pit mining that can become constraints. The constraint is often the nameplate throughput of the mill (Kanchibotla et al. 1998), though the other equipment can become bottlenecks depending on the fragmentation and hardness (Powell et al. 2015). For example, excess fines can lead to the ball mill becoming the constraint. In the pit, there is usually a wide access road that enables trucks to enter and exit simultaneously.

In the underground situation, there is more potential for constraints to develop and the constraints, or bottleneck, can move between the mine and mill depending on their relative capacities and the production demands. These include development, drawpoints, tip points, ore passes, declines, and shaft hoisting, as well as the plant processes noted previously, as shown in red in Figure 2 . In all the underground cases, these result from the need to move material through small openings and can be created by incorrect size and distribution of fragmentation. The paper considers the opportunities for blasting to create or destroy value within underground blasting operations. A brief review of blast design approaches indicates how the important 
considerations remain the ability to characterise the rock mass, rock strength of various applications and discuss how the in situ stresses need to be considered.

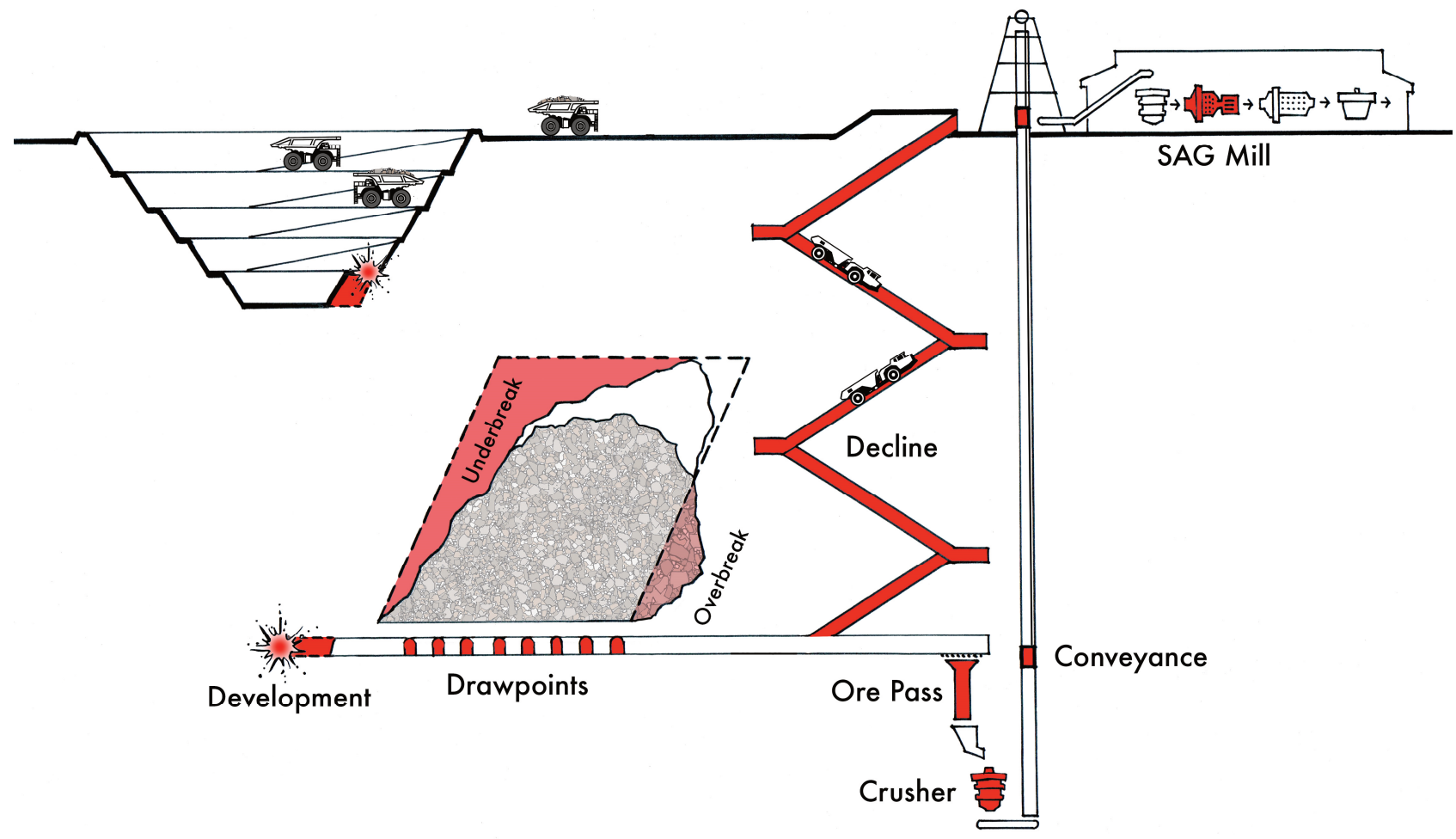

Figure 2 Schematic (not to scale) highlighting potential mine-to-mill throughput constraints (red) in open pit and underground operations

\section{$2 \quad$ Where is value created or lost by blasting in underground mines?}

One of the most important contributions of blasting to improving the mining value is in enabling consistent development. Increasing the development from $500 \mathrm{~m}$ per year to 7,500 m per year in a $600 \mathrm{kt} / \mathrm{a}$ mine, the NPV could be improved by $10.2 \%$ or AUD 5.4 million (Ebbels 2016), dependent on the practicality of increasing the drilling capacity. In many mines, haulage is the main constraint as a single truck width decline implies that loaded haul tucks must interact with unloaded trucks and other utility vehicles during their surface travel. Jumbo drills, longhole drills, raise boring, cemented fill, paste fill, and haulage were identified as bottlenecks in a case study of a longhole stoping gold mine (Fava et al. 2012). Haulage was identified as the constraint as the ore transport to the surface required an average of $7.5 \mathrm{~km}$ travel even though the mine had a maximum depth of $1,100 \mathrm{~m}$.

Value creation in the plant is derived from metal recovered from ore and the cost incurred in the energy required for grinding the rock fragments to micron size for flotation. To optimise value, the effects of rock mass fragmentation on the downstream processes must be considered in the blast design. These include the 3D distribution of grade, rock mass geomechanical, and geometallurgical parameters (McKay et al. 2016). Finer fragmentation proceeds through the semi-autogenous grinding (SAG) mill with minimal grinding so can create additional throughput (Kanchibotla et al. 1998). However, in the underground environment, excessive fines can create mud rushes in drawpoints and ore passes (Hadjigeorgiou \& Stacey 2013) that create safety risks and increase the load on production operations.

Geotechnical demands drive the ability to add additional value and mines that could have flexible mining schedules could increase NPV (Ebbels 2016). Stope performance is measured by the ability of miners to achieve maximum extraction with minimal dilution and ore loss (Sainsbury et al. 2015). Dilution is defined as any material (waste or backfill) which comes into an ore stream, reducing its value stope (Villaescusa 1995, 2014). Ore loss is unrecoverable economic ore left inside a stope (Villaescusa 1995, 2014). Dilution is mostly 
derived from overbreak. When the broken volume exceeds the planned extracted volume, it liberates waste material and decreases the ore grade. In operations where miner's KPIs are related to maximising tonnes to the surface, overbreak into grade can be seen as beneficial for individuals though affects the downstream by reducing head grade, reducing metal throughput in the plant, and creating difficulties to subsequent mining operations. The challenges with overbreak are that the additional volume increases filling times by requiring larger fill volumes that lead to fill overbreak in subsequent stopes. Also, overbreak has resulted from breakout with minimal explosive energy so the fragmentation follows the in situ block size distribution. If the blocks are coarse, they will create blockages in the stope resulting in longer mucking times.

Underbreak, defined as the volume of ore left in the stope due to insufficient breakage, leads to extra costs for secondary blasting and/or reduction of ore recovery the production (Guido et al. 2017). Secondary blasting campaigns applied to extract the missing ore generates damage in the walls and potential additional overbreak (Franklin et al. 1989; Germain \& Hadjigeorgiou 1997; Maerz et al. 1996b). Secondary blasting can only be done under specific conditions because usually once the stope is fired and emptied, the possibilities to drill into the underbreak are low or impossible, leaving two last options: extract the material while operating the adjacent stope or leave the material in place. Mine productivity can be increased by reducing re-work and unplanned rock handling associated with underbreak since reduced recovery drilling improves output by reducing production delays and decreasing the overall cost per tonne. Analytical equations and numerical and physical experiments have found that as few as five or six particles can cause arching (Török et al. 2017), e.g. model and experimental results in Figure 3. So, a $6 \mathrm{~m}$ wide drawpoint could be bridged by particles of around $1 \mathrm{~m}$. Additionally, to prevent orepass damage, grizzlies are installed at the tip points and large fragments will reduce throughput. At Olympic Dam, these are $900 \mathrm{~mm}$ to $1,200 \mathrm{~mm}$ at upper levels (Rose et al. 2016). The extent of overbreak and underbreak at Olympic Dam has been quantified extensively by Potvin et al. $(2015,2016)$.

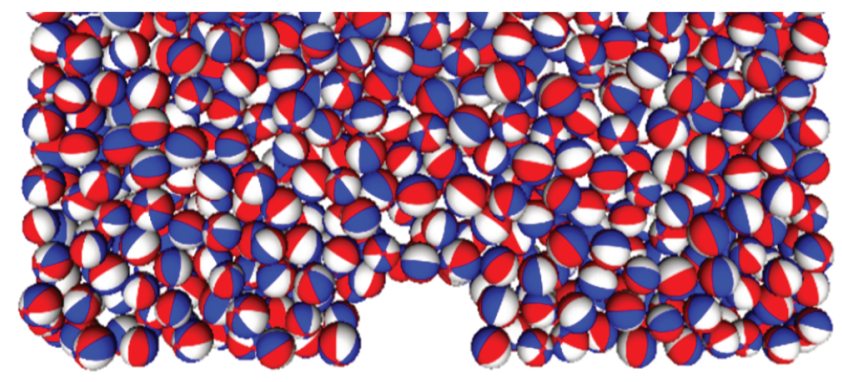

(a)

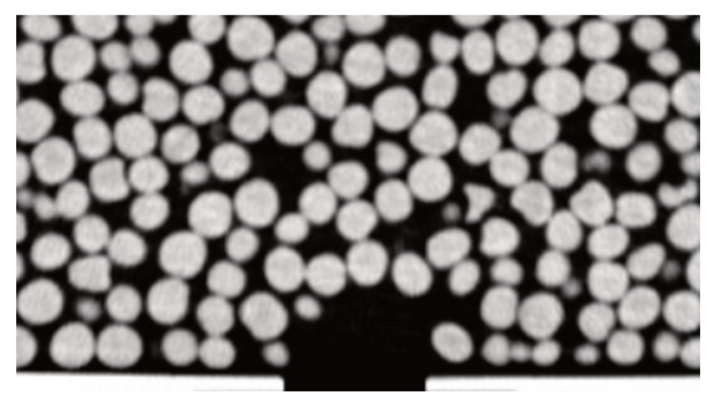

(b)

Figure 3 Clogging of opening simulating drawpoint or orepass using (a) Numerical methods; and (b) Experiments with peas (Török et al. 2017)

\section{Blast design approaches}

Underground blast design differs for tunnelling and underground construction (e.g. design of caverns) and stope mining. Drill and blast design for tunnelling and underground construction is as mature as the surface blasting operations. Significant works have been done to develop approaches for the efficient excavations of tunnelling by drill and blast operations. Examples of such designs can be found in reference books such as Gustafsson (1973), Jimeno et al. (1995), Langefors \& Kihlstrom (1973), and Olofsson (1990).

Gustafsson (1973) discussed some of the basic empirical Swedish approaches developed for the design of ring blasting for stope mining. Similarly, Jimeno et al. (1995), Persson et al. (1993), and Brady (2004) summarised a few of the existing blasting methods for underground mining. The blast design and the associated rock fragmentation are critical elements of underground mining. The editors of the Handbook of Underground Mining Methods (Hustrulid \& Bullock 2001), which is known as the main reference of underground mining, allocated one chapter in this reference book just to discuss the principles of underground blast design. The chapter provides a good review of the approaches that can be used for the 
design of underground blast patterns (Holmberg et al. 2001). However, the design of rings for stope blasting is often based on rules of thumb (AECl 1980a,1980b; Onederra \& Chitombo 2007) and require improvement.

Investigations of ring blast design through small-scale (lab-scale) modelling is an approach supported by LKAB via the Luleå University of Technology. There, Rustan $(1990,2012)$ found that pre-existing discontinuities play a dominant role in the fragmentation of ore in sublevel caving. Later, Hamoudeh (2013) showed that changing the drill design from a fan pattern to the parallel pattern proposed by Hustrulid \& Kvapil (2008) resulted in a finer fragmentation in comparison to the corresponding standard ring design. Similarly, Iqbal (2013) showed that using double rings and selecting proper delay intervals can help to achieve a more uniform and finer fragmentation.

There is a limit to the success of small-scale model studies to capture the complex mechanisms of rock breakage in ring blasting. Numerical modelling which can replicate the non-linear behaviour of the rock and explosives can be used to explore the mechanisms of rock fragmentation in underground blasting (Sellers et al. 2010). Few attempts have been made to numerically investigate the mechanism of stope blasting due to the complexity of the physics and the size of the models required. Furtney et al. (2016) used the hybrid stress blast model (HSBM), a 3D continuum-lattice model, to compare sublevel cave mining designs for potential underground operations at the De Beers Venetia mine in South Africa. The model includes the process of detonation, crushing, and fragmentation of the rock mass and the muck pile formation. Figure 4a shows how damage and fragmentation can be predicted for a ring design and Figure $4 \mathrm{~b}$ shows the equivalent rock mass swell after blasting. The model has some limitations in that the crushed zone is axisymmetric, does not include shear response or rotational degrees of freedom, and the in situ stress is constant though produced median fragment sizes similar to those predicted using a Kuz-Ram approach. Modelling was done with the transient dynamic elasto-plastic 3D LS-DYNA finite element package (Yi et al. 2017). It is not possible to explicitly create blast-induced fragmentation finite element models so a geometric approach is used to identify the formation of 3D blocks. The model indicates fracturing as high regions of plastic strain or damage, as shown in Figure 4c. Fragmentation is identified by searching for undamaged zones between the implied fractures and these blocks can be used to identify the spatial distribution of fragments, as shown in Figure 4d. Longer delay times produced finer fragmentation for the cases discussed in the paper. The results also showed that the middle primer and the top primer in sublevel caving (SLC) can give a finer fragmentation.

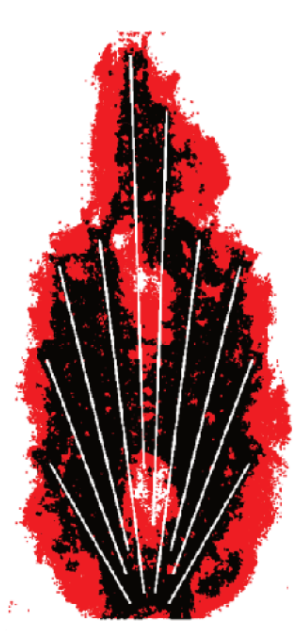

(a)

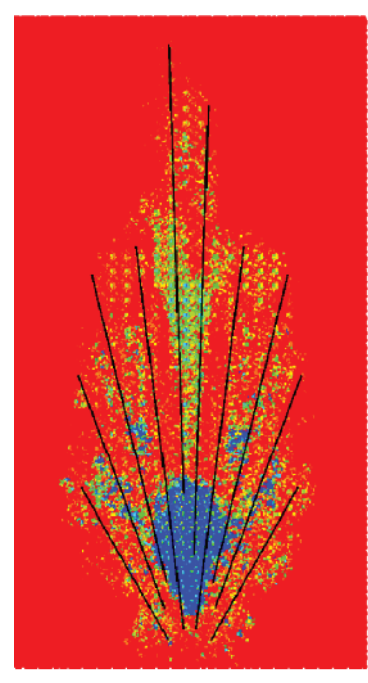

(b)

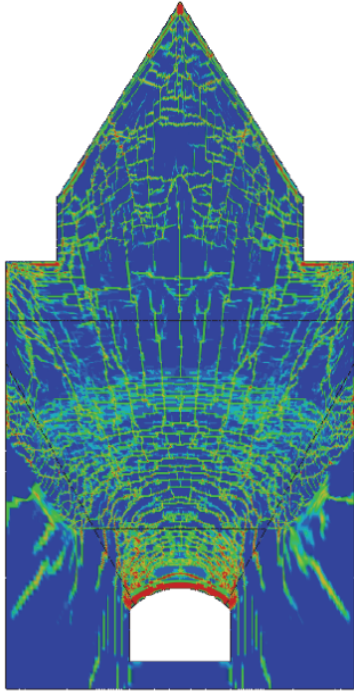

(c)

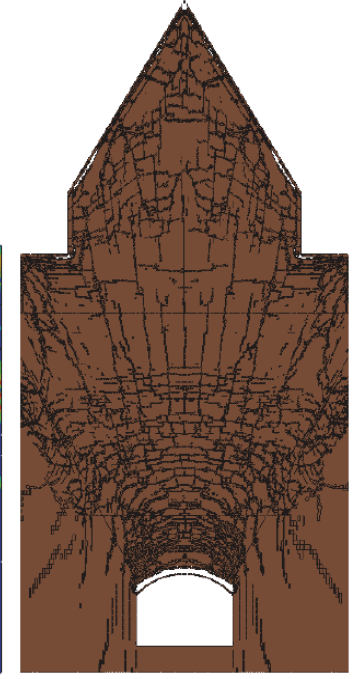

(d)

Figure 4 Comparison between numerical modelling of ring blasting. (a) Partial damage (red) and complete fragmentation (black); and (b) Swell predicted by hybrid stress blast model (Furtney et al. 2016) compared with (c) Plastic strain distribution and (d) Fragmentation predicted using LS-DYNA (Yi et al. 2017) 
The combined finite-discrete element method parallelised on the GPGPU can model the fracture and fragmentation process combining the influences of in situ stress field, equation-of-state based blast loading, fracturing in tension, and shear with gas flow loading of fractures required for the complex dynamic interactions from multiple blast rounds. Figure $5 c$ shows the damage induced by a ring firing predicted by a preliminary analysis (D Fukuda \& H Han, pers. comm. 17 September 2020) using the 3D/FEM DEM numerical model (Fukuda et al. 2019; Han et al. 2020) to begin to numerically investigate the mechanisms of 3D rock fragmentation and throw in ring blasting. The associated movement of 3D fragmentation formed in the blast is shown in Figure $5 \mathrm{~d}$.

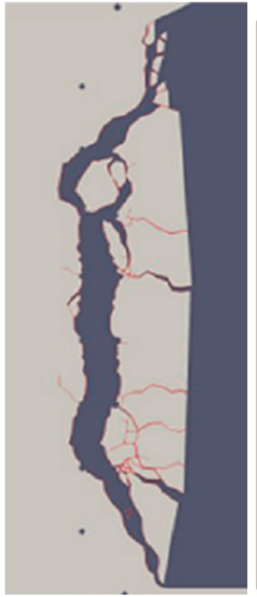

(a)

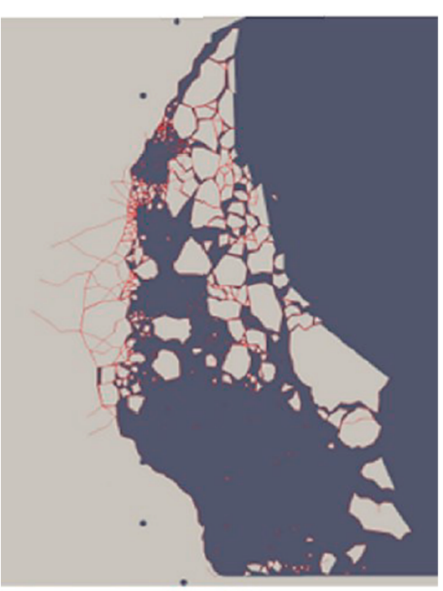

(b)

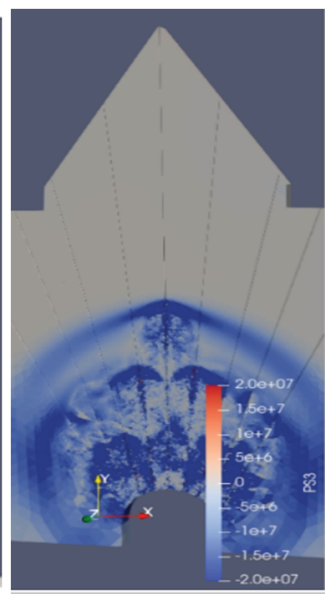

(c)

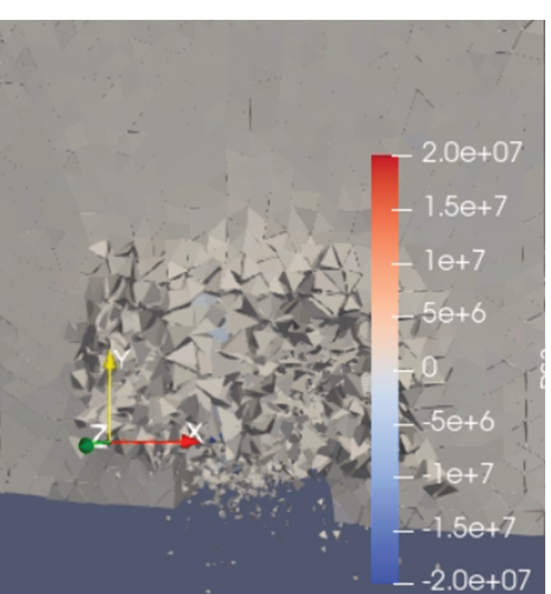

(d)

Figure 5 Comparison of (a) Simultaneous timing with (b) 6 ms delays between holes (Han et al. 2020); (c) Preliminary outcomes of 3D FEM/DEM numerical modelling (D Fukuda \& H Han, pers. comm. 17 September 2020); (d) Associated movement of 3D fragmentation formed in the blast

Conventional ring design aims at a uniform distribution of explosives through the stope. However, in the majority of cases, this is just a compromise. In practice, there is a considerable difference between the specific charge at the toe, middle section, and the collar of the blastholes. Averaging the powder factor to feed into a fragmentation model (e.g. Kuz-Ram) may involve a considerable error in the computations. To fix this problem, Singh \& O'Connor (2007) proposed the concept of 'cell powder factor' for ring blasting where the fragmentation is selected based on the energy distribution in a 3D grid surrounding the ring design.

\section{How does the rock mass structure affect value creation?}

Rock mass characteristics and properties are important factors in blast design. Understanding the influence of the geological discontinuities and the physicomechanical properties of rocks in the outcomes of fragmentation is crucial to improving the drill and blast operation for mine-to-mill optimisation (Adhikari \& Gupta 1986, 1989). Geological structures such as joints and faults play a huge role in determining the rock-excavation interaction that is disproportionate to the space they occupy and are often unknown hazards.

The behaviour of rocks around rock excavations is controlled by the block size dimension (Palmström 2000). A proper understanding of the network of discontinuities is required for the underground mines. Numerous approaches have been proposed up to the present to help rock engineers to precisely estimate the dimension/volume of in situ blocks in a jointed rock mass (Elmouttie \& Poropat 2012; Hardy 1993; Kluckner et al. 2015; Palmström 2000; Wang et al. 1991; White 1977). Discontinuity spacing, number of joint sets, and persistence control the in situ block size distribution (IBSD) in a rock mass (Lu \& Latham 1996). 
Similar approaches were proposed by other researchers. For example, Hardy (1993) and later Hardy et al. (1997) reported on an empirical equation originally developed by White (1977) to estimate the IBSD in a jointed rock mass. White's distribution function was originally developed for block cave mining. According to this approach, the percentage of blocks smaller than a given size $\mathrm{x}$ (by weight or volume) can be estimated by:

$$
P(x)=1-\lambda^{3} \exp (-\lambda x)\left(\frac{x^{3}}{6}+\frac{x^{2}}{2 \lambda}+\frac{x}{\lambda^{2}}+\frac{1}{\lambda^{3}}\right)
$$

where:

$$
\begin{aligned}
& P(x)=\text { expressed as a fraction. } \\
& x=3 \text { D block size. } \\
& \lambda \quad=\text { reciprocal of the mean core intercept length. }
\end{aligned}
$$

Hardy et al. (1997) stated that White's equation generally results in acceptable outcomes when rock quality designation( RQD) is less than 50\%. However, for rock masses with higher RQD values, blocks shapes tend to change based on size. Therefore, the block size distribution achieved based on Equation 1 might be somewhat limited. Moreover, the application of this equation is limited to rock masses that contain well developed joint networks, where core intercept length can be estimated using a negative exponential function like $f(x)=100 e^{-\lambda x}$. White's distribution function has been used for the primary design of blasting in several open pit mines in Australia and resulted in the acceptable prediction of the IBSD in bench rocks (Scott \& Onederra 2015).

Azarkovich \& Pokrovskii (1991) stated that the Weibull statistical distribution can be used for evaluating the fractional composition of the natural blocks in rock masses. Based on this approach the fraction of blocks with size less than $x(m)$ can be estimated by:

$$
P(x)=\left(1-\exp \left(-\left(\frac{x}{b_{m}}\right)^{c_{m}}\right)\right)
$$

where:

$$
\begin{aligned}
& b_{m}=\text { distribution scale parameter. } \\
& c_{m}=\text { distribution shape parameters. }
\end{aligned}
$$

The research performed by the authors of this paper showed that the values of these parameters can be defined as follow:

$$
b_{m}=k_{1} \cdot\left(S_{j a}\right)^{k_{2}}, c_{m}=k_{3} \cdot\left(S_{j a}\right)^{k_{4}}
$$

where:

$$
\begin{array}{ll}
S_{j a} & =\text { average joint spacing in meter }(\mathrm{m}) \text { and is defined as } S_{j a}=1 / \lambda . \\
\lambda & =\text { fracture frequency. } \\
k_{1}, k_{2}, k_{3}, \text { and } k_{4} & =\text { site constants (need to be estimated based on field investigation). }
\end{array}
$$

Azarkovich \& Pokrovskii (1991) proposed values of $k_{1}=1.40, k_{2}=1.25, k_{3}=1.65$, and $k_{5}=0.125$ for the rock masses that they investigated for rockfill dam construction. For example, Figure 6 shows the outcomes of the IBSD prediction that the authors have performed through the modified Azarkovich \& Pokrovskii and White models for a rock mass with a fracture frequency $(\lambda=6.0)$ presented in Wang et al. (2003). As can be seen, the model can provide a good estimation of the IBSD. 


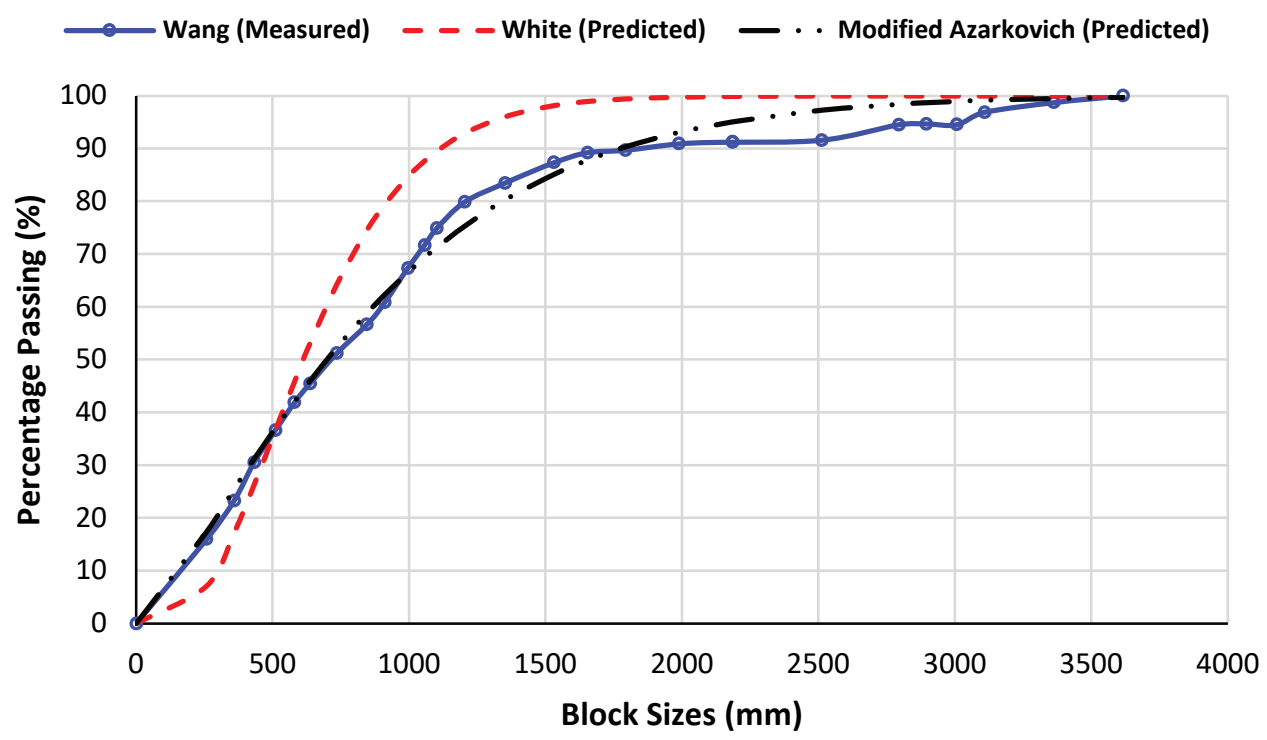

Figure 6 The prediction of White (Hardy et al. 1997) and modified Azarkovich \& Pokrovskii (1991) models against the measured IBSD from Wang et al. (2003)

It is not only the IBSD of the rock mass that affects the blast outcomes. Figure 7 illustrates how larger-scale structures can cause overbreak and underbreak (Miller et al. 2004). Overbreak occurs when rock mass is severed from the surrounding support by a structure and falls into the open stope. Underbreak can occur, for example, when the explosives in the toe of the blasthole are cut off by movement on the structure by prior holes or rings firing.
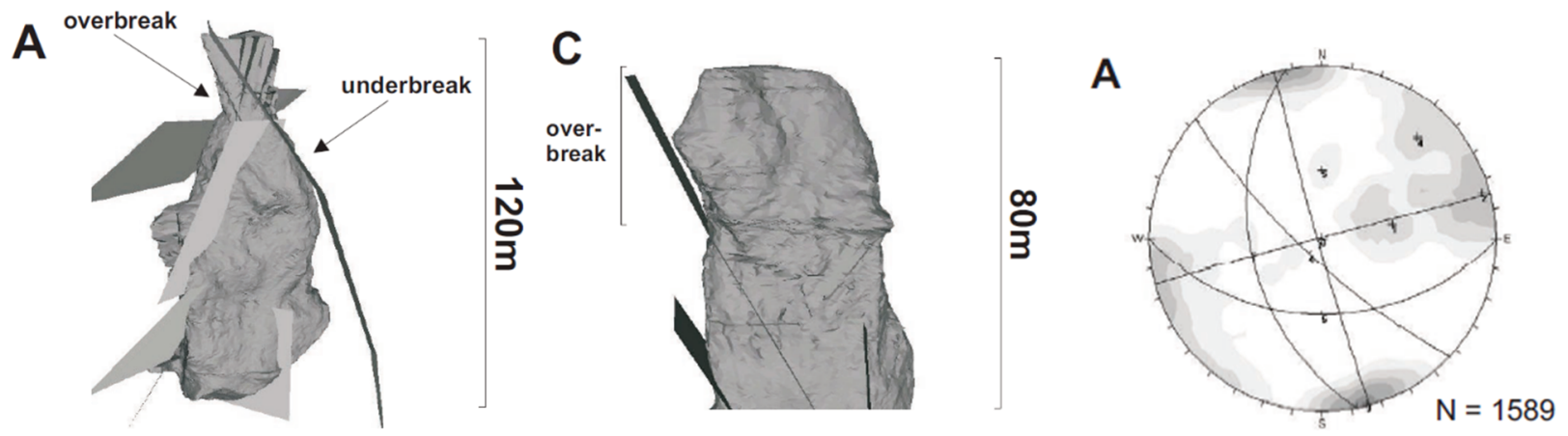

Figure 7 Effect of larger-scale structures on stope underbreak and overbreak at Olympic Dam (Miller et al. 2004)

Research by Tyupin \& Anisimov (2018) on the effect of geological, geophysical, and geomechanical characteristics in complex-structure ferruginous quartzite ore bodies at the Kursk Magnetic Anomaly on blasting and processing performance indicated that rock mass anisotropy in both small and large scales is important to consider. Anisotropy from the genesis of ore bodies and large-scale structures such as faults, the pivots of anticline and syncline folds, core and wings of folds, and the orientation of bedding alters the outcomes of the rock fragmentation and can result in severe overbreak and underbreak and ore loss.

\section{$5 \quad$ What strength should we use?}

When considering a database of rock strength tests, the usual geotechnical and blasting practice is to apply the average strength. Not all the tested samples are intact and so many of the samples will fail on discontinuities, providing a lower average strength. To illustrate the effect, a set of strength values from an underground hard rock mine are shown in Figure 8. Various rocks have different levels of variability though 
there is a more or less linear trend with increasing mean strength. The use of the average strength may not make much difference with weaker rocks, but when the rock strengths are high, then there is a significant difference. In geotechnical design, the lower strength values are conservative for excavation failure. Since blasting and processing are influenced at a smaller scale, it seems prudent to select strengths at the higher percentile, e.g. 95\% (i.e. mean plus 2 standard deviations) when designing the blast or considering the overall processing hardness, especially of pebbles. Removal of test data from samples that failed on weaknesses is easy with rigorous laboratory uniaxial compression strength (UCS) testing and more difficult with field point load testing.

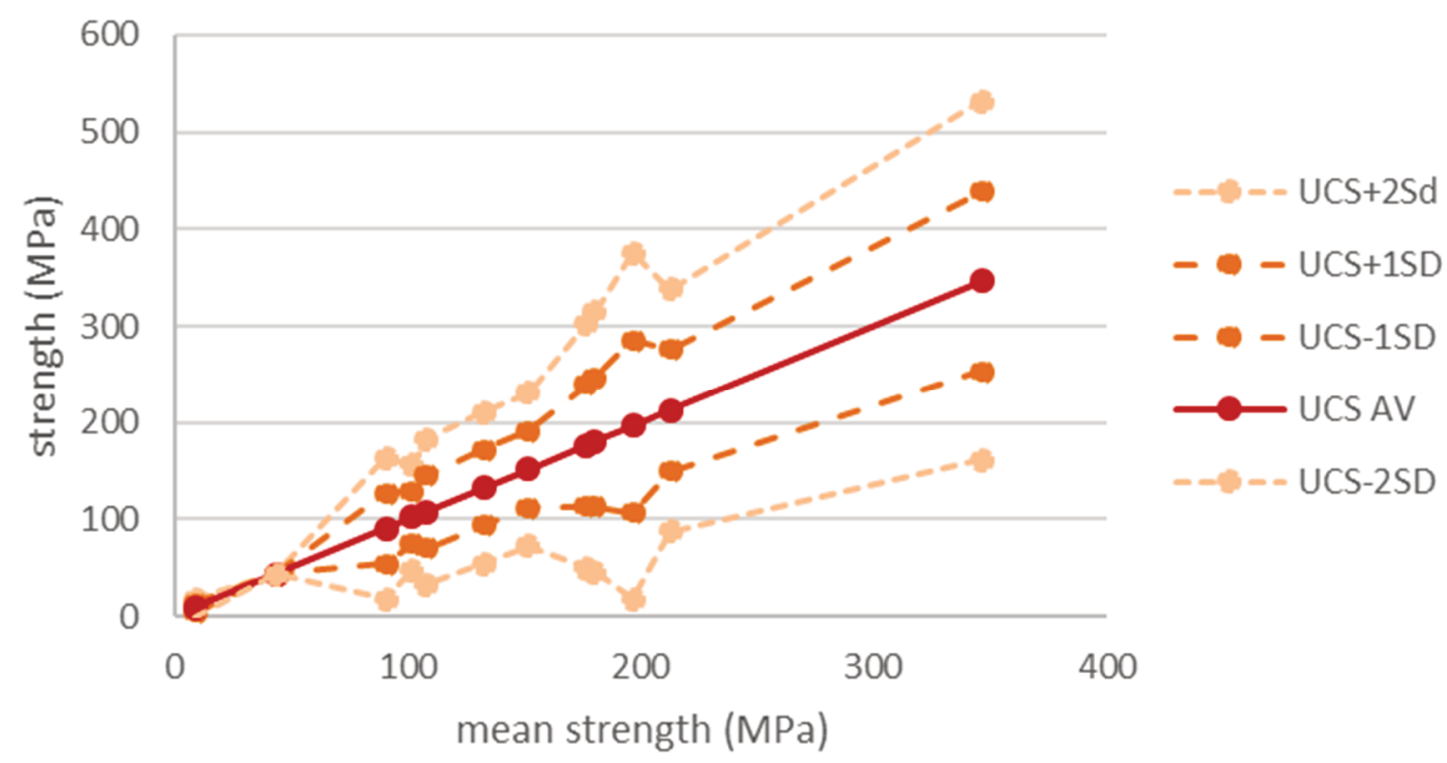

Figure 8 Rock strength variation with increasing average strength from a hard rock mine

Having determined that the rock strength in geotechnical terms is open to interpretation, it is important to understand how the blast design and processing engineers interpret strength. All rock particles going to heap leach, as well as to the processing plant, need primary crushing. A jaw or gyratory crushers are commonly used for the primary crushing of rocks. Casali (1990) used Bond's third theory of comminution (Bond 1952) to estimate the required specific energy ( $\mathrm{kWh} /$ tonne) of primary crushers:

$$
C R_{s e}=10 \times B W i \times\left(\frac{1}{\sqrt{P_{80}}}-\frac{1}{\sqrt{F_{80}}}\right)
$$

where:

$$
\begin{aligned}
& P_{80}=80 \% \text { passing sizes in the product of the crusher (in microns). } \\
& F_{80}=80 \% \text { passing sizes in the feed of the crusher (in microns). } \\
& B W i=\text { Bond's work index showing the resistance of materials to crushing and grinding. }
\end{aligned}
$$

$B W i$ is defined as the energy ( $\mathrm{kWh}$ per short ton) that is needed to break rocks with, theoretically, infinite size to materials with $80 \%$ passing size equal to 100 microns (Bond 1952). It is also noted that the short ton is a mass measurement unit equal to 2,000 pounds mass which is slightly smaller than 1 metric tonne (1 short ton $=907.18474 \mathrm{~kg} \approx 0.907$ tonnes).

The Bond work index, BWi, may be estimated from UCS or Young's modulus $E_{r}$ (Deniz \& Ozdag 2003; Vatandoost 2010). For example, Abdel Haffez (2012) proposed the following relationships for this purpose.

$$
B W i=5.7 \times \ln (U C S)-9.5=6.3 \times \ln \left(E_{r}\right)-10.6
$$


Figure 9 shows how these relationships fit the data for the compression strength and elastic modulus of the rocks studied.
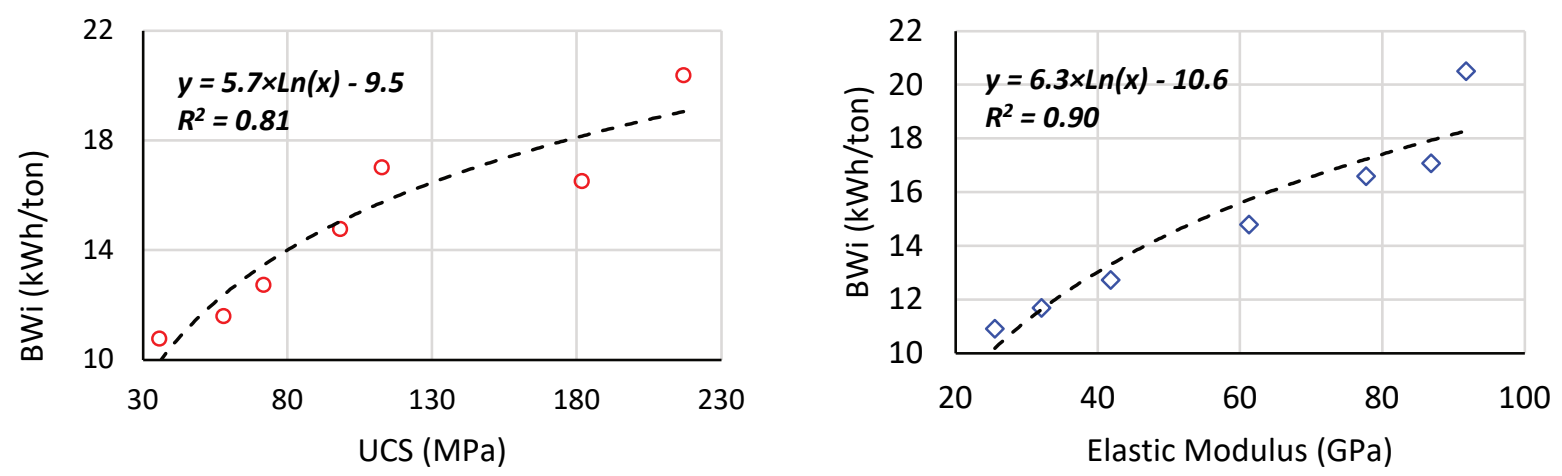

Figure 9 The relationship between BWi and the rock Young's modulus uniaxial compression strength (Abdel Haffez 2012)

There are also revised versions of Bond's theory such as the model that was proposed by Morrell (2009). However, the estimation of the input parameters of this model needs specific tests. For example, one of the main parameters is the crushing ore work index which is directly estimated based on the proprietary SMC Test ${ }^{\circledR}$.

The next stage in the process may contain autogenous grinding (AG) mills that use the larger rocks to grind the smaller ones or SAG mills which are fed with about $12 \%$ of metal balls to assist the grinding (Morrell 2004). Ball load is often changed in the range of 0 to $18 \%$ (Morrell 2004). There are many approaches available to compute the energy consumption in processing equipment. Based on Morrell's model, the SAG mill's specific energy ( $\mathrm{kWh} /$ tonne) can be estimated by (Morrell 2006):

$$
S A G_{s e}=\frac{K \times F_{80}^{c_{1}} \times D W i^{c_{2}} \phi^{c_{4}} f(A r)}{\left(1+c_{3}\left(1-\exp \left(-c_{5} \times J\right)\right)\right)}
$$

where:

$$
\begin{array}{ll}
J & =\text { fraction volume of balls. } \\
\Phi & =\text { mill speed (fraction of the critical speed). } \\
f(A r) & \text { function of mill aspect ratio (length/diameter). } \\
c_{1}, c_{2}, c_{3}, c_{4} \text {, and } c_{5}= & \text { constants. } \\
K & =\begin{array}{l}
\text { function whose value is dependent upon whether a pebble crusher is } \\
\text { in-circuit (if there is a pebble crusher in the circuit then } K=0.95, \text { otherwise } \\
\end{array} \\
K=1.0 \text { ) (Morrell 2004, 2011). }
\end{array}
$$

Throughput (tonnes/hour) can be estimated as:

$$
T=P / S A G_{s e}
$$


By keeping the mill power $P(k W)$ constant, if the other mill parameters are kept constant too, then mill energy depends on the strength through the drop-weight index (DWi) and the $80 \%$ passing size crushed Run-of-Mine (ROM) fragmentation feed size $F_{80}$. The $D W i$ can be estimated from conventional geomechanics tests based on the following relationship with point load data extracted from curve-fitting on data presented at (Morrell 2004) (Figure 10):

$$
D W i=1.9136 \times\left(P L S_{p b}\right)^{0.6502} R^{2}=0.9025
$$

where:

$P L S_{p b}=$ post-blast point load strength index of fragmented muck pile and can be related to the UCS and the blast-induced damage factor $0<D<1$.

$$
P L S_{p b}=(1-D) P L S_{b b}=(1-D) \mathrm{UCS} / 24
$$

where:

$D=$ represents the effects of blasting on the strength of rock particles (Murr et al. 2015) and varies between 0.1 and 0.4 based on experimental tests (Katsabanis 2020; Katsabanis et al. 2005).

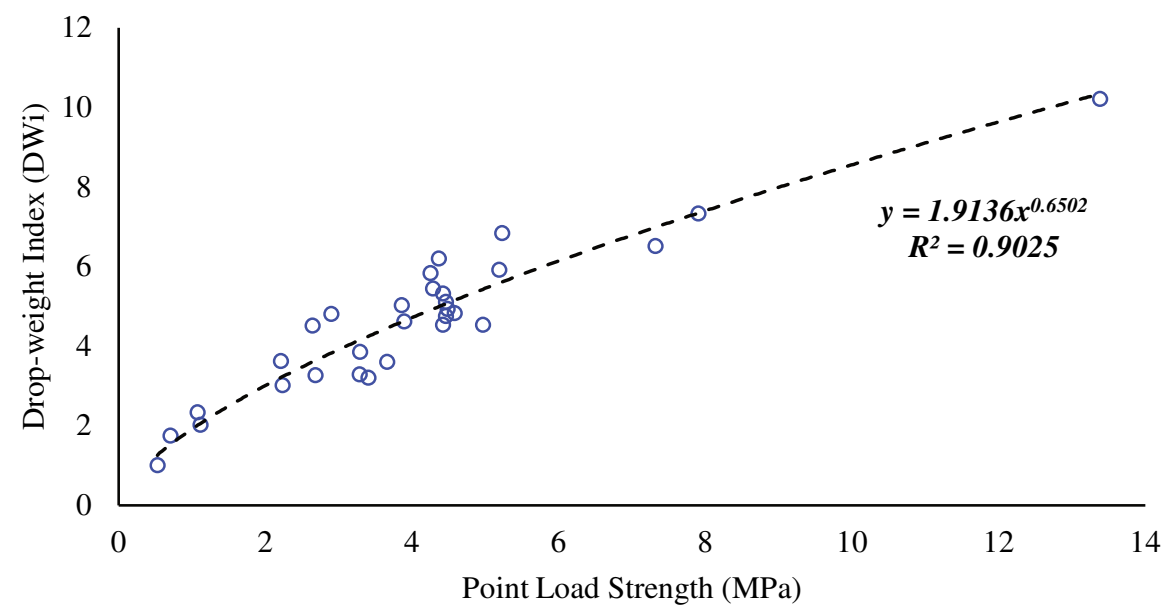

Figure 10 Relationship between drop-weight strength and point load strength (data extracted from Morrell 2004)

The mine-to-mill approach works because increasing the fines content by higher energy blasting will increase throughput (McKee 2013; McKee et al. 1995). However, the use of $F_{80}$ in the mill throughput prediction model provided in Equation 6 depends only on the $80 \%$ passing feed size $F_{80}$. This is not well correlated with the fines and, after crushing to a given closed side setting, does not change much at all. More complex models are required to model the effect of the fines through the mill. For this research, the increase in throughput with fines is calculated based on data provided by (Kanchibotla et al. 1998). The relationship between throughput and percentage passing $10 \mathrm{~mm}$ is extracted and compared for the two approaches including the Morrell and JKSimMet models (Morrison \& Richardson 2002) (Figure 11). The authors have processed the data presented by Kanchibotla et al. (1998) and extracted the following simple relationship for estimating the additional throughput $\mathrm{dT}$ (tonnes/hour) from fines relative to $12 \%$ passing $10 \mathrm{~mm}$ :

$$
d T=20.411\left(P_{-10 \mathrm{~mm}}-12\right)
$$

where:

$P_{-10 \mathrm{~mm}}=$ percentage of the ROM fragmentation feed passing $10 \mathrm{~mm}$. 


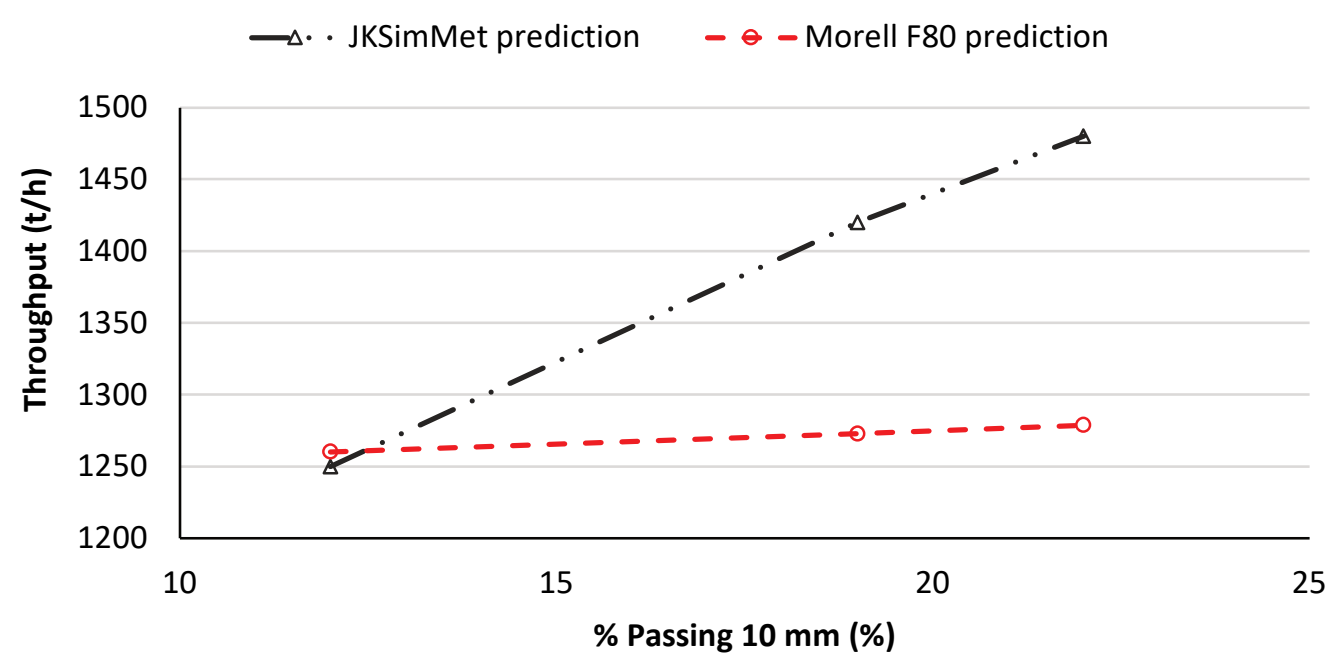

Figure 11 Effect of fines on throughput comparing the F80 model and the JKSimMet model

However, not all smaller particles are beneficial to throughput. There is a range of critical sizes from $25 \mathrm{~mm}$ to $150 \mathrm{~mm}$ that are difficult to grind (Silva \& Casali 2015). Observations in four different mines and laboratory tests were used to predict the effect of critical size on specific energy and the power consumption in SAG mills. The SAG mill specific energy is suggested to be:

$$
S A G_{s e}=0.063 \times(P(150)-P(25))+75.3 \times J b-45 \times N N c+18.3 / S c w
$$

where:

$$
\begin{array}{lll}
S A G_{s e} & = & \text { specific energy of SAG mill. } \\
(P(150)-P(25)) & = & \text { fraction of the fresh feed in the size range } 25 \text { to } 150 \mathrm{~mm} . \\
J_{b} & = & \text { bulk fraction of the SAG mill volume occupied by the balls charge. } \\
N N_{c} & = & \text { fraction of the critical speed. } \\
S_{c w} & = & \text { solid concentration by weight (\%). }
\end{array}
$$

A major issue of the model is that it does not incorporate the effects of the mechanical characteristics of rocks (e.g. hardness or toughness) on the outcomes of comminution. Other alternative models use parameters such as Bond work index, drop-weight index, or $A^{*} b$ to account for the rock hardness (Bond \& Whitney 1959; Morrell 2004; Shi \& Kojovic 2007).

\section{$6 \quad$ Predicting fragmentation for throughput}

Unlike surface blasting where the explosive distribution can be well controlled, ring blasting is often more complex. Often a single position in standard-sized drift is used to drill the holes required for an entire ring. Each hole in the ring is angled to a specific orientation (Singh \& O'Connor 2007) and holes can be several times longer than the height of the drift. Controlling the direction of long holes in a limited space can be challenging and considerable hole deviation may occur. Lith et al. (2004) applied the conventional Kuz-Ram model to sublevel stoping mines in Sweden, though could not properly predict the particle size distribution (PSD). Later, Liu (2006) tried to modify the original Kuz-Ram model (Cunningham 1983) for underground mining using a few factors to account for the effects of rock fragility, applying delay times and the pattern geometry. Small-scale and large-scale studies of ring blasting in magnetite ore in the SLC mine in Kiruna by Wimmer et al. (2008) and Wimmer (2012) showed that the rock fragmentation mechanisms follow the 'natural breakage characteristics', which was previously suggested by Grasedieck (2006), within the fines region. Numerous field and laboratory studies at the Luleå University of Technology resulted in the development of the Swebrec (also known as KCO) fragmentation prediction model (Ouchterlony 2005a, 
2010b; Ouchterlony et al. 2006). KCO is one of the most accurate models available for the prediction of rock fragmentation in surface mining. The research recently performed by Ouchterlony et al. (2017) showed that the Swebrec is matched with the basics of a generic fragmentation model which is known as the fragmentation-energy fan. This shows that KCO can be used for general applications such as underground mining. The KCO model is defined as:

$$
P(x)=1 /[1+f(x)] \text { with } f\left(x_{\max }\right)=0, f\left(x_{50}\right)=1
$$

where:

$$
\begin{aligned}
& P(x)=\text { fraction passing size } x(\mathrm{~mm}) . \\
& x_{\text {max }}=\text { maximum block size }(\mathrm{mm}) \text { (fixed point on the curve). } \\
& x_{50}=\text { median block size }(\mathrm{mm}) \text { (fixed point on the curve). }
\end{aligned}
$$

Ouchterlony (2005a) showed that a proper function for $f(x)$ could be:

$$
f(x)=\left(\ln \left(\frac{x_{\max }}{x}\right) / \ln \left(\frac{x_{\max }}{x_{50}}\right)\right)^{b}
$$

where:

$$
\text { factor } b=\text { curve undulation parameter. }
$$

Many relations may be used to estimate the value of $b$ (Ouchterlony 2005b) and

$$
b=n \times \ln (2) \times \ln \left(\frac{x_{\max }}{x_{50}}\right)
$$

where:

$$
\begin{aligned}
& n=\text { uniformity index in the original Kuz-Ram model (Cunningham 1983). } \\
& x_{50}=\text { average (median) fragmentation size in mm (Ouchterlony et al. 2006). }
\end{aligned}
$$

This parameter can be estimated using the well-known (Kuznetsov 1973) equation modified by Cunningham (1983) or the more general formulation proposed by Ouchterlony (2010a).

Additionally, $x_{\max }$ denotes the upper limit of the blast fragmentation size and is assumed to be the largest in situ block size on the bench. The parameter $x_{\max }$ is an important parameter in the Swebrec model and depends on the geometry of discontinuities as well as the pattern of blasting. Ouchterlony (2005b) proposed the following relation for approximating $x_{\max }$ :

$$
x_{\max }=\min \left(S_{j}, S, B\right)
$$

where:

$$
\begin{aligned}
S_{j} & =\text { in situ joint spacing. } \\
S & =\text { blasthole spacing. } \\
B & =\text { burden. }
\end{aligned}
$$

As a simple approach, Chertkov (1985) showed that the largest blocks in a rock mass can be estimated as:

$$
x_{\max }=5 / \lambda
$$

where:

$\lambda=$ fracture frequency of the jointed rock mass.

The authors have implemented the Liu and Swebrec models in a spreadsheet and predicted the outcomes of ring blasting in an underground open stope copper operation in Chile. Examples of the results for different fracture frequencies of $\lambda=5.0$ are shown in Figure 12. However, Wimmer (2012) performed some field measurements at the Kiruna mine to investigate the fragmentation results of ring blasting and the suitability of the KCO function for the prediction of fragmentation. Although the KCO can provide a good prediction of 
fragmentation, he observed a relative flattening of the sieving curves due to the selective breakage in the mid-range ( 25 to $73 \mathrm{~mm}$ ) and an increased amount of fines in magnetite ores which cannot be captured by the original Swebrec model. However, adjusting the fitting routines to weight the squared residuals by $1 / \sqrt{x}$ in the fines region improves the fit (Wimmer 2012).

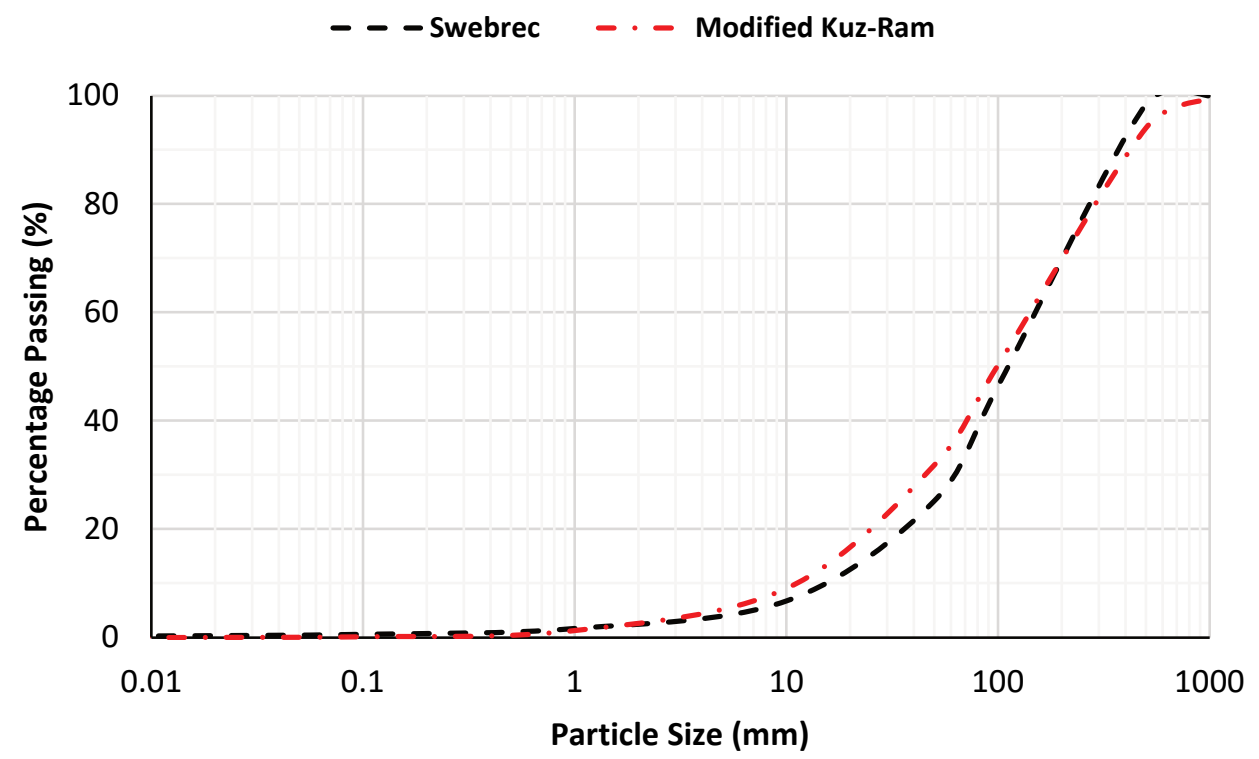

Figure 12 Comparison of Swebrec and Liu fragmentation prediction approaches

\section{$7 \quad$ Fragmentation measurement}

Numerous efforts have been devoted to developing techniques for the rapid characterisation of rock masses in benches and stopes and the measurement of rock fragmentation in muck piles (Ghosh \& Daemen 1993; Widzyk-Capehart 1998). Image/photo analysis techniques have been among the most widely used approaches for this purpose (Bedair 1996; Hunter et al. 1990; Singh 1986). For example, Kemeny et al. (1993) discussed the fundamentals of the development of an image analysis approach for rock fragmentation assessment. The work performed by Kemeny and his co-workers resulted in the development of the Split-Desktop ${ }^{\circledR}$ (Kemeny 1994) which is widely used for fragmentation measurement in mining engineering (Devgan 1992; Kemeny et al. 1993). Similarly, the separate work performed by Franklin and Maerz resulted in the development of WipFrag (Franklin et al. 1988; Maerz et al. 1996a). Kemeny et al. (2006) also proposed the application of the ground-based LiDAR (laser scanning) for the pre-blast rock mass characterisation. This approach has been significantly developed and is widely used for rock mass characterisation in civil and mining engineering projects (Fekete \& Diederichs 2013; Riquelme et al. 2014).

Bamford et al. (2016) also tested the application of unmanned aerial vehicle (UAV) technology for the collection of images from the muck piles to overcome the errors that can be introduced by human applications. These days, drones are widely used for the analysis of rock fragmentation, especially in surface mining. Latham et al. (2003) also investigated the performance of four different image analysis software including FragScan (Schleifer \& Tessier 1996), PowerSieve (Chung \& Noy 1996), Split (Kemeny 1994), and WipFrag (Maerz et al. 1996a) against the sieved data related to some well-designed artificial muck piles. The outcomes of this study indicated that each system has its own merits and drawbacks. Proper calibration is needed for each software to ensure that the fragmentation prediction outcomes are accurate.

Sanchidrián et al. (2006) also investigated the applicability of image analysis for the prediction of the rock fragmentation in blasting. The results showed that proper calibration is needed to improve the prediction. While using image analyses, fine sizes tend to be the more underestimated as they become more abundant. The outcomes were improved by introducing the fine adjustment factor which is estimated based on field 
calibration. Sanchidrián et al. (2009) also tried to fit the Rosin-Rammler and the Swebrec distribution on the image processing data and to extrapolate to the non-delineated fines. The error between the sizes measured and the sizes of the reference distributions increase from the coarse to fine. Thurley et al. (2015) also proposed using 3D image data from stereo photogrammetry for the automated measurement of the fragmentation at LKAB Kiruna sublevel cave mine. The results were compared against the sieved data. Although the size distribution measured based on these two approaches did not agree well, the research showed that image processing can still provide a useful estimation of the large size classes and a bulk estimation of the fine materials below approximately $60 \mathrm{~mm}$.

Often, photo analysis techniques cannot predict the fragmentation well in the underground environment. Campbell \& Thurley (2017) have, therefore, used a high-resolution 3D laser scanning method to overcome the problem of the conventional image-based analysis technique and to develop a rapid approach for the fragmentation measurement in the underground mining environment (Figure 13). The approach has been successfully implemented for fragmentation assessment at the Ernest Henry sublevel cave mine. The application of the technique involved significant testing and calibration at the site (Campbell \& Thurley 2017). However, the prediction of the details of the fines component requires further research.

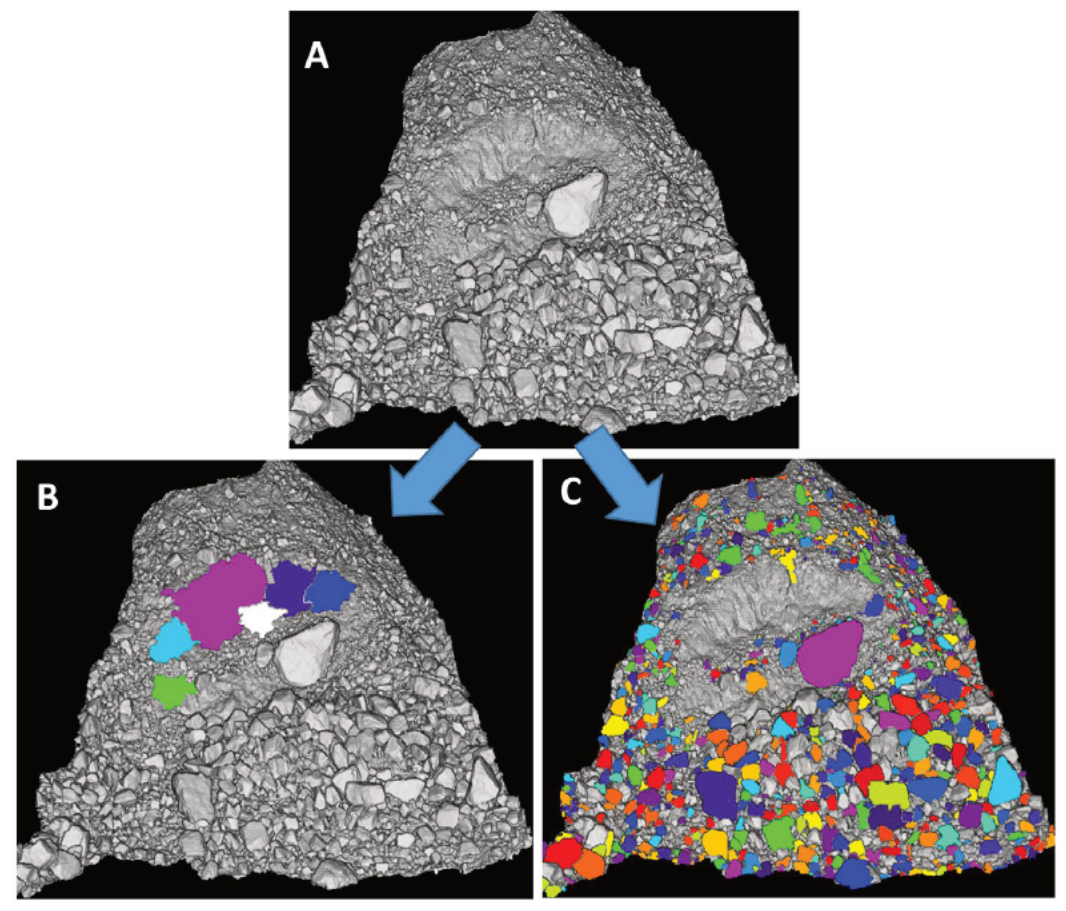

Figure 13 An example of a laser scan and particle delineation. (a) Scanned muck pile; (b) Detecting the area of fines; (c) Identifying non-overlapped fragments) (courtesy of Campbell \& Thurley 2017)

\section{The need to consider in situ and mining-induced stress}

A challenge with all analytical fragmentation approaches for the underground environment is that none consider the in situ or mining-induced stress state. The detonation of explosives in the hole leads to high-pressure gas-phase products that lead to the crushing of surrounding rock and the work done by the gas to expand the borehole leads to additional fracturing. Detonation theory assumes 'ideal', effectively infinite confinement strength and stiffness (Braithwaite 2012). Conventional blast energy partitioning theory (e.g. Lownds 1986) implies that rock is elastic and so high rock stiffness leads to high shock stresses in the rock, which act to create fragmentation and heave. More recent studies (Cunningham et al. 2007; Sellers et al. 2012) consider the geomechanics of the interaction between the explosives and rock suggesting that the rock yielding and crushing means that the borehole pressure must have rapidly reduced by the plastic expansion of the borehole into an equilibrium state with the rock post-failure response for the given confining stress. The equilibrium pressure then further reduces as the borehole expands with time and the 
cracks extend to the nearest free surface where the pressure drops totally as the gas vents. A simple 1D model for each of these mechanisms has been developed (Furtney et al. 2012) that shows that considering reduced blasthole pressures in equilibrium with the rock stresses led to improved predictions of burden velocity. More recent, 2D coupled finite element-smoothed particle hydrodynamics (FEM-SPH) modelling (Lu et al. 2016) indicated that the in situ stress has little effect on the crush zone of the borehole through the significant effect on the extent of the fracturing zone surrounding the blast (see Figure 14).

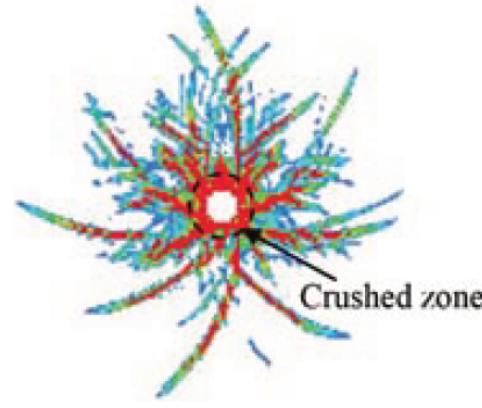

ANFO in granite

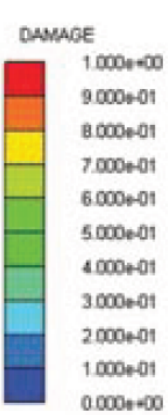

$0.000 \mathrm{r} * 00$

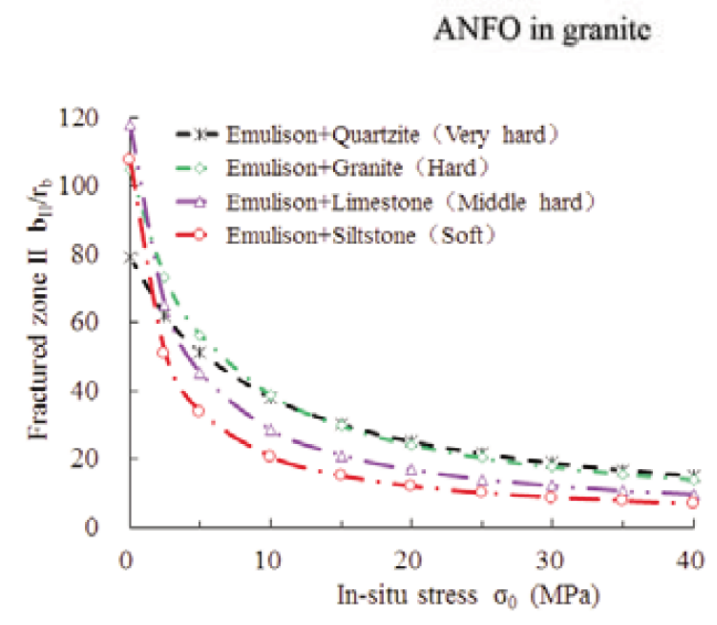

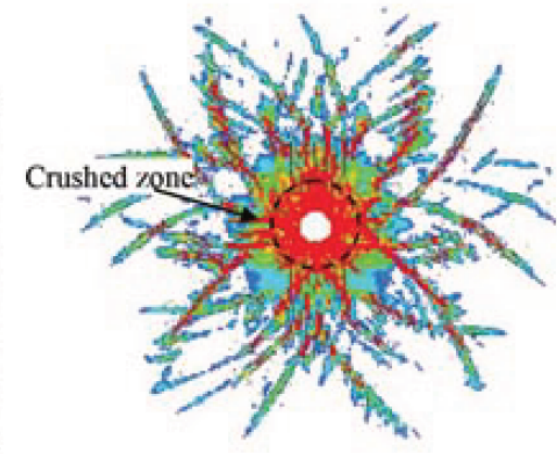

Emulsion in limestone

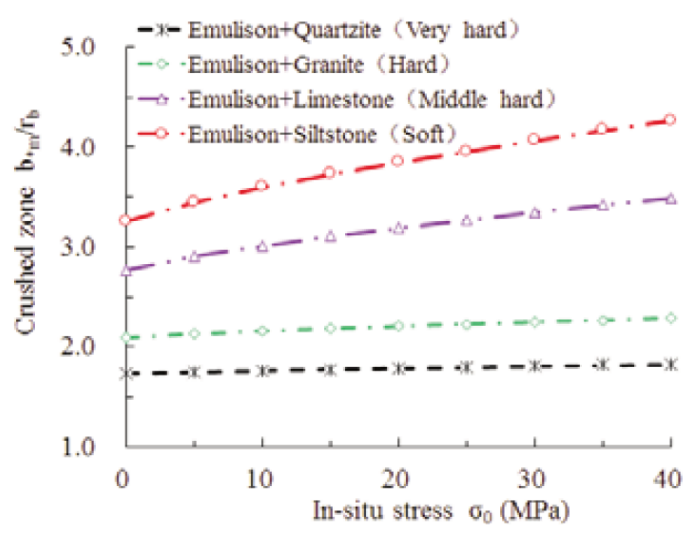

Figure 14 Finite element-smoothed particle hydrodynamics (FEM-SPH) modelling showing (a) The effect of rock type and explosive on the fracture zone extent; (b) The effect of in situ stress on crush zone; and (c) The effect of in situ stress on fracture extent (Lu et al. 2016)

To illustrate the effect of the in situ and subsequent mining-induced stress state on the confinement of the points around a stope to be fired, we consider the example of a stope at Olympic Dam mine showing overbreak and underbreak provided by Potvin et al. (2016) and reproduced in Figure 15. The original paper does not discuss the effect of in situ stresses and estimations are required. The stress state in Olympic Dam is expected to show sub-horizontal maximum principal stress about 2.5 to 2.7 times the vertical stress (Meyer et al. 2010) and is orientated at the bearing of about $130^{\circ}$ to $140^{\circ}$ (Fowler \& Weir 2008). The minor stress is about 1.5 times the vertical stress (Meyer et al. 2010). A simple, 2D FLAC model was run to understand the effect of the angled principal stress on the region where the rings will fire after the slot is excavated. Figure 16 shows how the principal stress difference is higher on the south side, indicating that the south is closer to failure, hence the overbreak. The north side has higher compression states. The values of the principal stresses at points along the potential stope boundary with distance from the slot are shown in Figure 16. Three Hoek-Brown failure envelopes are shown for comparison, considering high strength-massive Geological Strength Index, high strength-blocky and low strength-very blocky rock parameters (Brady 2004) based on the Olympic Dam data (BHP 2011). The south side point where the first ring will fire $(-2 \mathrm{~m})$ is outside the failure envelope. Overbreak will occur with the first ring and reduce with distance from the slot, as shown in Figure 15a. On the north side, the first ring has high confinement. The potential for the holes to not break 
the toe burden is high. Once the first ring has fired, the confining stresses will curve southwards and the subsequent rings will become more and more confined, leading to increasing underbreak, as shown in Figure 15a.

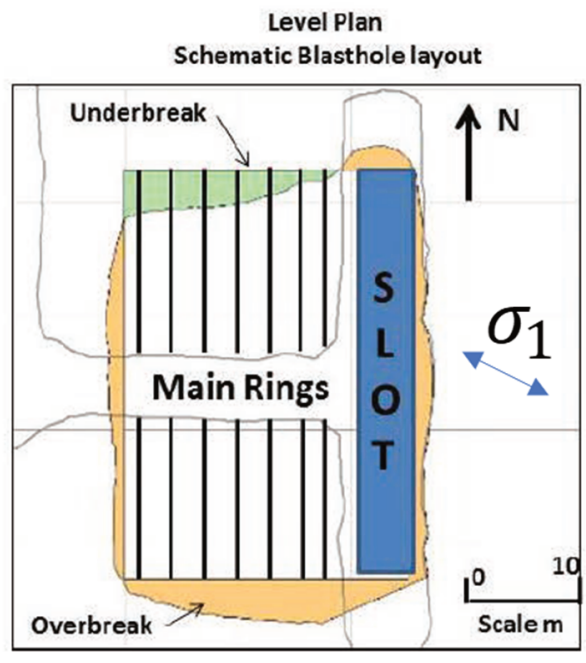

(a)

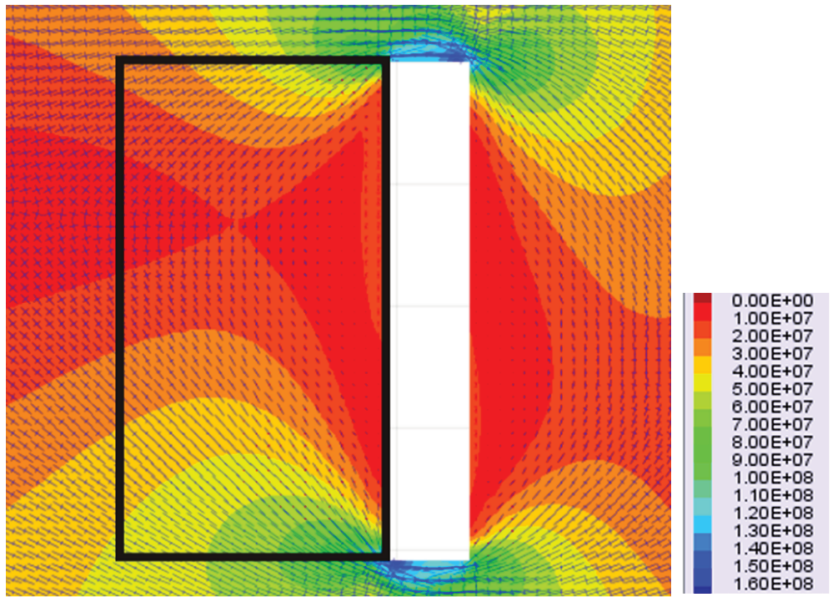

(b)

Figure 15 Effect of in situ stress on overbreak and underbreak using: (a) Stope from Potvin et al. (2016) with stress state (indicative) added by authors from Fowler \& Weir (2008); and (b) Principal stress vectors and contours of principal stress difference $(\mathrm{Pa})$ from elastic FLAC model

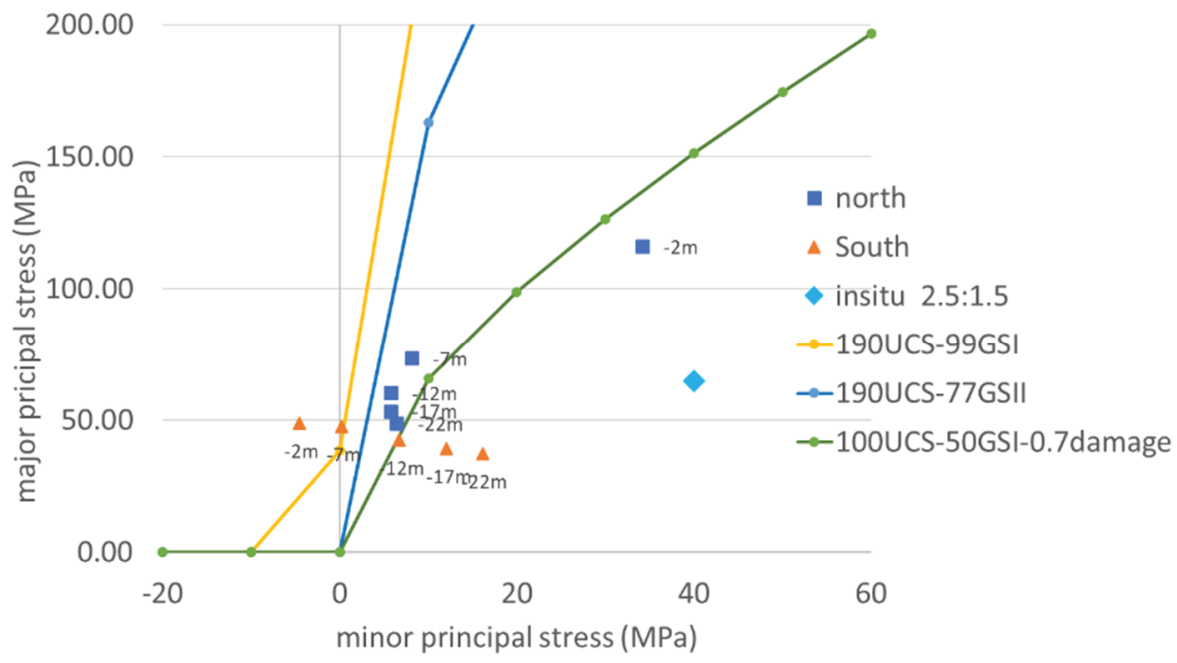

Figure 16 Principal stress states on the north and south sides of planned stope after the excavation of the slot using an elastic FLAC model and compared to three Hoek-Brown failure model options

\section{Solving current problems with data fusion}

Conventionally, borehole logging and field mapping of discontinuities are performed to estimate the IBSD in a rock mass. Exposure of discontinuities is seldom available underground and the exposed discontinuities in a tunnel may not be representative of discontinuities in nearby stopes. Accurate estimation of properties such as 3D spatial distribution, persistence, and trace length is even more difficult (Wang et al. 1991). In particular, the persistence of discontinuities is an important characteristic of discontinuities controlling the number of in situ blocks.

Kemeny et al. (2002) also proposed an integration approach based on drilling data to prepare a database of the in situ rock mass characteristics and the fragmentation measurement through image analysis (Split 
package) to provide some information related to the post-blast muck pile. The fusion of the data on a hole-by-hole basis will allow the optimisation of blast patterns.

Currently, block models have limited information for improving the rock mass characterisation, and access to data for design and reconciliation of blasting outcomes is limited (Jackson \& Sellers 2017). Recently, autonomous drone systems are beginning to become available. For example, Hovermap is a mobile LiDAR scanner and navigation system with an on-board computer (Jones et al. 2020) that can, in real-time, generate a point cloud of the scanned environment. The Hovermap simultaneous localisation and mapping (SLAM) approach links real-time LiDAR sensing to the drone control and adds artificial intelligence to enable the craft to fly anywhere through a defined excavation whilst keeping distant from the walls. A significant increase in the ability to quantify features is enabled by the Hovermap point clouds of 5,000 points $/ \mathrm{m}^{2}$ compared to the 3 points $/ \mathrm{m}^{2}$ typical of the standard cavity monitoring system (CMS) scan.

A case study of a stope at a mine in northern Queensland, Australia, is used in Figure 17 to illustrate how this data can be integrated with other technology to improve blast design. The stope is at a depth of $320 \mathrm{~m}$ at the base, has dimensions of $20 \mathrm{~m}$ long, $23 \mathrm{~m}$ wide, $68 \mathrm{~m}$ high, the rock mass is composed of a single rock type, has an average RQD of 82 , is surrounded by three filled stopes (north, south, and west), and is agreed to have reasonably good stability and performance. A zone near a large fault comprises $65 \%$ of the total $8.2 \%$ of underbreak so integration with design software can highlight where design holes are outside broken stope, e.g. indicating underbreak as shown in Figure 17b. Fusion with the blast energy distribution plots from JKSIMBLAST in Figure 17c shows how superimposing the planned blast energy distribution onto the Hovermap point cloud can indicate the discord between the actual blast pattern design and the final shape. For the example in Figure 17c, only a single blast energy distribution plane is provided for clarity though in an on-screen visualisation, the user can move around and see the continuous fusion of the blast energy and the perimeter of the broken region. From this information, the limit of the excavation can be calibrated to roughly coincide with a powder factor of $0.72 \mathrm{~kg} /$ tonne, which is represented in the blast energy distribution by the transition from green to blue in Figure 17c. The lower hole has fired properly and created a semicircular excavation. However, the intersection of the point cloud with the design centres of the upper holes (red-grey contours) indicates that these holes have not broken the rock as intended, leaving a zone of underbreak.

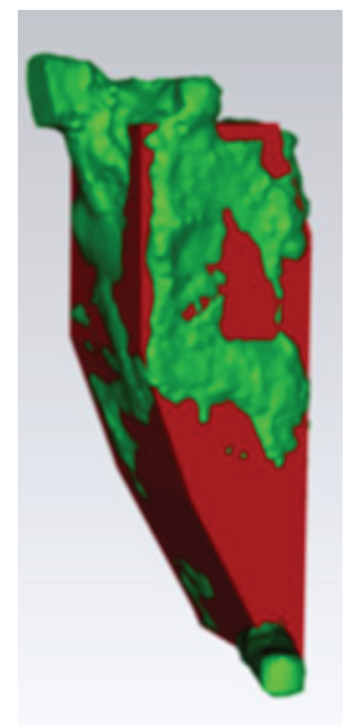

(a)

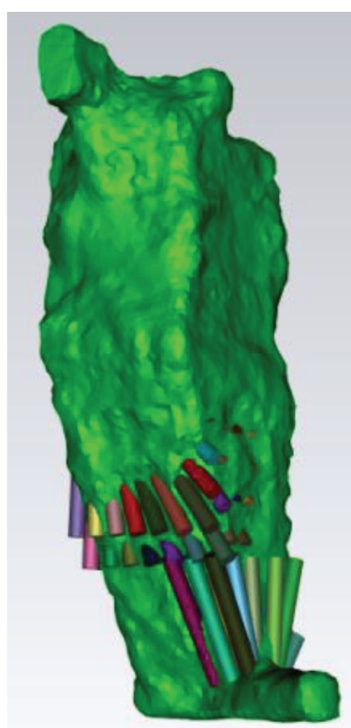

(b)

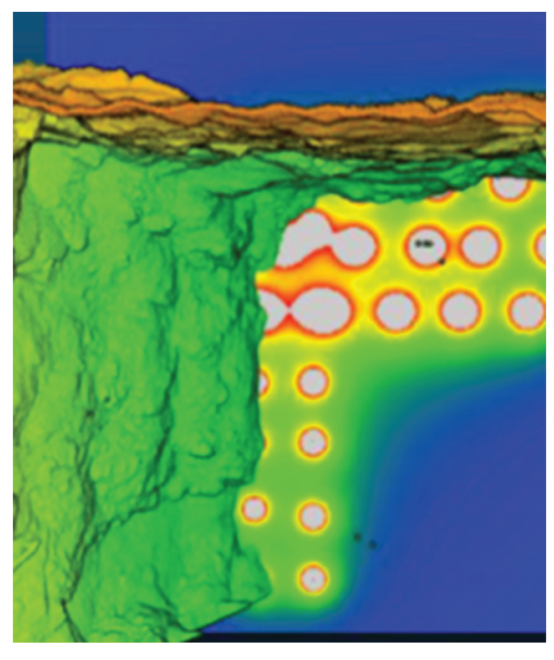

(c)

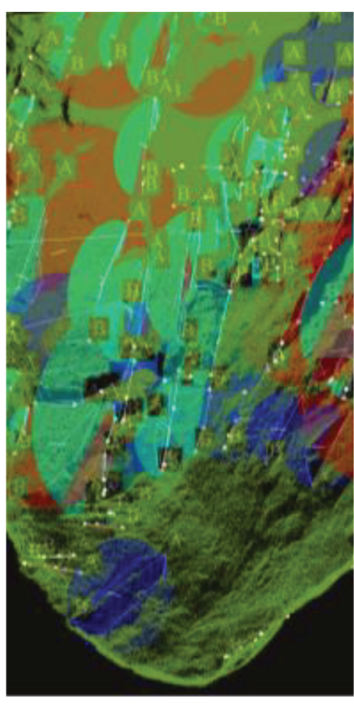

(d)

Figure 17 Stope over and underbreak study comparing Hovermap scan to (a) Design shape and (b) Design blast pattern; (c) Integrated with JKSIMBLAST blast energy contours and (d) SIROVISON joint recognition 
More research is required to calibrate the blast energy relative to the rock strength, fracturing, and mining-induced stress state. The link between blast design and geological structure is considered by starting to link the Hovermap scans with SIROVISON software updates designed for surface blast design (Jian et al. 2018). A small section of the stope with automatically recognised features is shown in Figure $17 \mathrm{~d}$. At this stage, the potential effect of geological structures and their orientation on stope performance is inconclusive, because the quality of the point cloud at the bottom of the stope is low which makes structural recognition difficult. Other factors such as the hole deviation still need to be considered.

More recently, several studies have been done to explore the application of a 3D laser scanning technique for the characterisation of rock masses in underground excavations for civil and mining applications (Fekete 2010; Fekete et al. 2010; Lato \& Vöge 2012). The analyses have shown that when the technique is applied correctly and the data are properly processed and interpreted, it can provide a rapid and detailed 3D characterisation of the rock mass. In particular, the geometrical characterisation of discontinuity surfaces including location, orientation, frequency, and large-scale roughness can be obtained. Despite the limitation of the approach, the outcomes seem promising. It is also easy to use the technique in the field. For example, Figure 18 shows an example of the application of 3D LiDAR for the characterisation of rocks and discontinuities in a tunnel. The integration of the approach with 3D DEM modelling will allow us to identify the discrete fracture network and the areas prone to instabilities (Fekete 2010). This technique can also be useful for identifying the IBSD and degree of the natural fracturing of the rock mass for blast design in underground stopes.

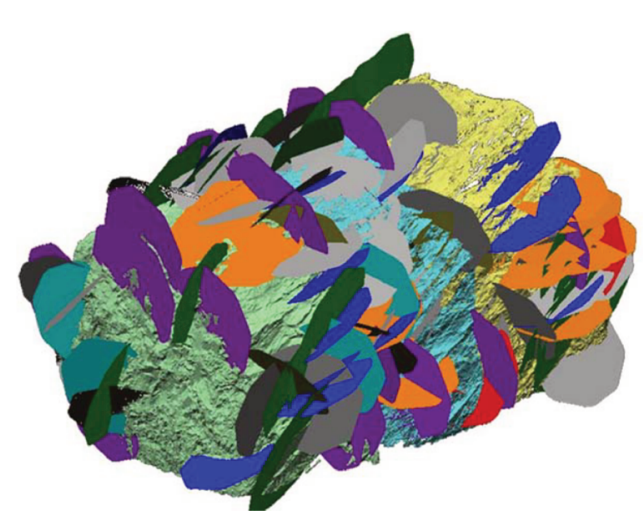

(a)

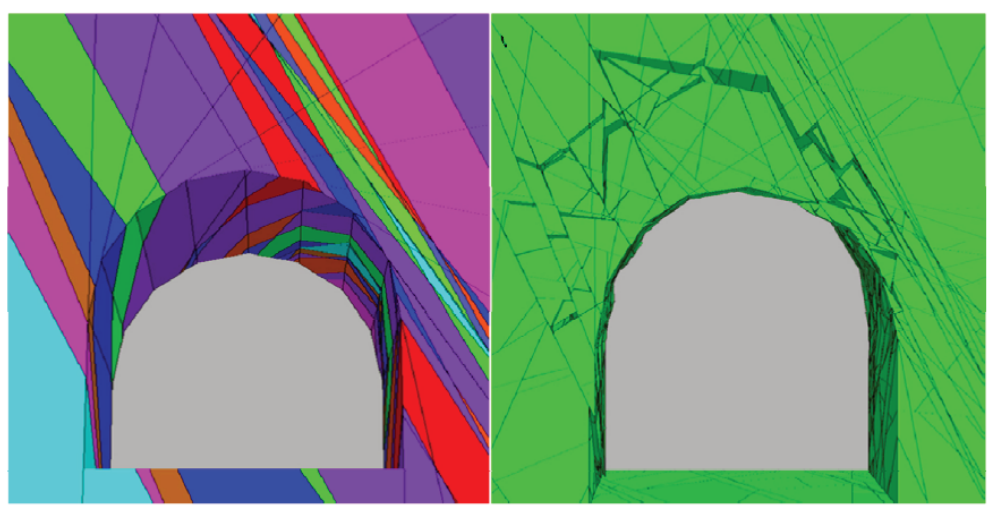

(b) (c)

Figure 18 (a) Extrapolation of major joint surfaces; (b) 3D block model constructed based on the discontinuities identified by LiDAR scanning; and (c) Block movement in a 3D DEM model, highlighting potential instability issues (Fekete 2010)

For a case study of how rock mass strength, structure, stress, and the geometrical constraints induced by underground stoping can be integrated, a mine-to-mill study at an underground open stoping mine is considered (Jackson \& Sellers 2017). The blast improvement was enabled by the development of blasting related indices (BRIs) to quantify variations in rock strength and structure for each lift of each stope and each stope indices were derived from combinations of lengths along with the drillcore from underground diamond drilling because the simplifying assumptions contained in the block model prevented differentiation between waste rock strengths in rock mass characteristics. For illustration, Figure 19a shows the coverage from typical underground drilling from another mine. Calibration of the results enabled adjustments to the blast design based on the rock mass conditions and accordingly improved the blast outcomes. The uniformity of the in situ rock mass affects the rock along with the actual in situ block sizes.

Coherent stopes will have the same IBSD and incoherent stopes will have a mix of coarse and fine, as shown in Figure 19b. A coherent but coarse stope could produce larger blocks leading to process and bogging issues, as well as the possibility of underbreak and poor recovery. Coherent but fine stopes may result in overbreak and critical size for the mill, especially if the rock is strong. Incoherency complicates the blast outcomes as there is spatial variability across the blast rings. Possible challenges include drilling issues and deviation, 
explosive product leakage from blastholes, blast energy being channelled into the weaker or finer rocks, and not breaking the oversize with blocks falling out between lifts causing production delays. New technologies are required to obtain a full 3D picture of the rock mass and build a design-time structural model for the blast engineer.

The availability of multiple blastability indices can focus the designer on improving production by creating correct designs that improve fragmentation, reduce underbreak, and predict overbreak. By plotting the BRI combinations for stopes in sequence, as shown in Figure 19c, the blast designs can be tailored to ensure that the best products can be achieved and integrated into short- and long-term planning for the mine and the mill. The cumulative effect of stress state is complex and a damage model based on plastic strain (Beck et al. 2013) has been used to estimate the cumulative degradation of the rock mass. If the rock mass properties can be differentiated geometrically between the rock inside the stope, then the ratio of properties (e.g. ratio of inside to surrounding strength), aligned with the coherence, can indicate underbreak or overbreak potential.

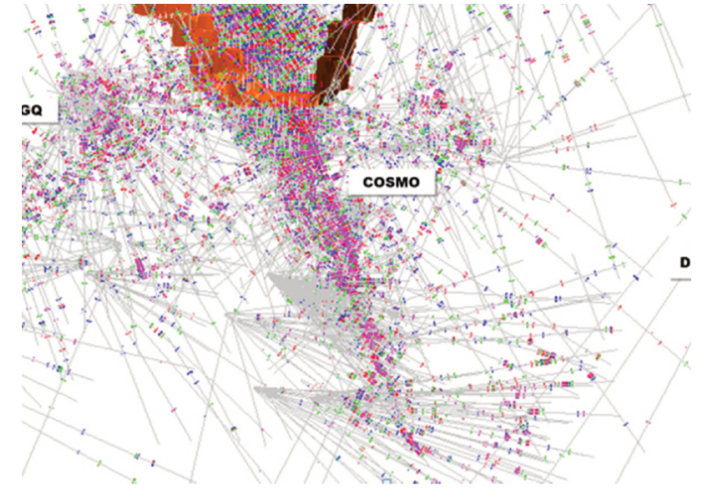

(a)

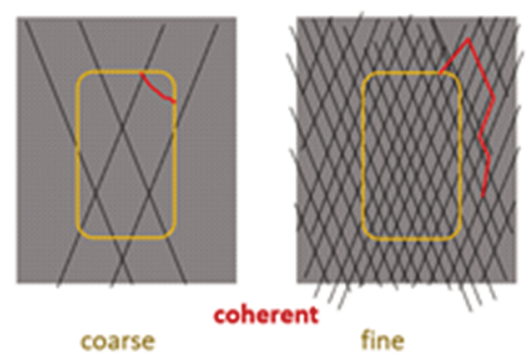

fine

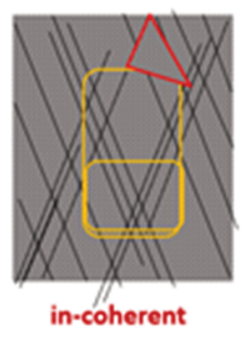

(b)

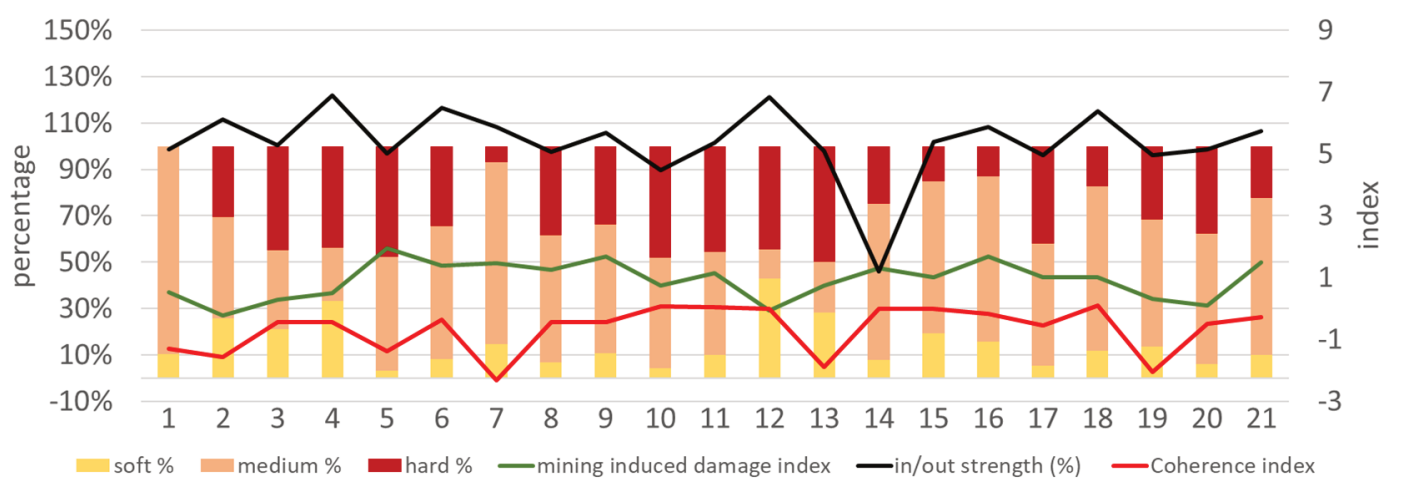

(c)

Figure 19 Data fusion from grade control drilling with (a) Example of drilling from Sunrise Dam; (b) Schematic of classification of defects by spacing and coherence and the implications for blast design; and (c) Sequence of stopes from a mine in Queensland showing the relative percentages of soft, medium and hard rock in each stope along with relative indications of damage, coherence, and strength of inside stope to outside

To demonstrate the linkage of these concepts of strength and rock mass structure to throughput outcomes for a given blast design, Monte Carlo simulations have been performed for a single blast design on a range of different stope characteristics. The results of 5,000 simulations, equivalent to about 5-10 years of mining, are shown in Figure 20. For illustration, we selected the rock strength and median fracture frequency randomly for each stope from relevant normal distributions. It is noteworthy that the non-linearities in the 
distributions are combined. Even with the simplified choice of a normal distribution of median fracture frequency, a skewed distribution of maximum sizes is created. Combining these with a normal distribution of strengths, the non-linear fragmentation and process models lead to a very skewed distribution of process throughput when using the $F_{80}$ model of Equation 7 . The throughput will become more normally distributed about a much higher average value if the effect of the fines is considered with the linear approach of Equation 10. A total increase in throughput over the Life-of-Mine will create significant additional value. Note, however, that the ability to create value depends on the magnitude of the throughput constraint relative to the distribution of potential throughput and would indicate the potential for changes to blast design to improve value. Typically, the nameplate throughput of the mill can be the constraint or, more often in the underground situation, the throughput of the mining process that drives the value creation.
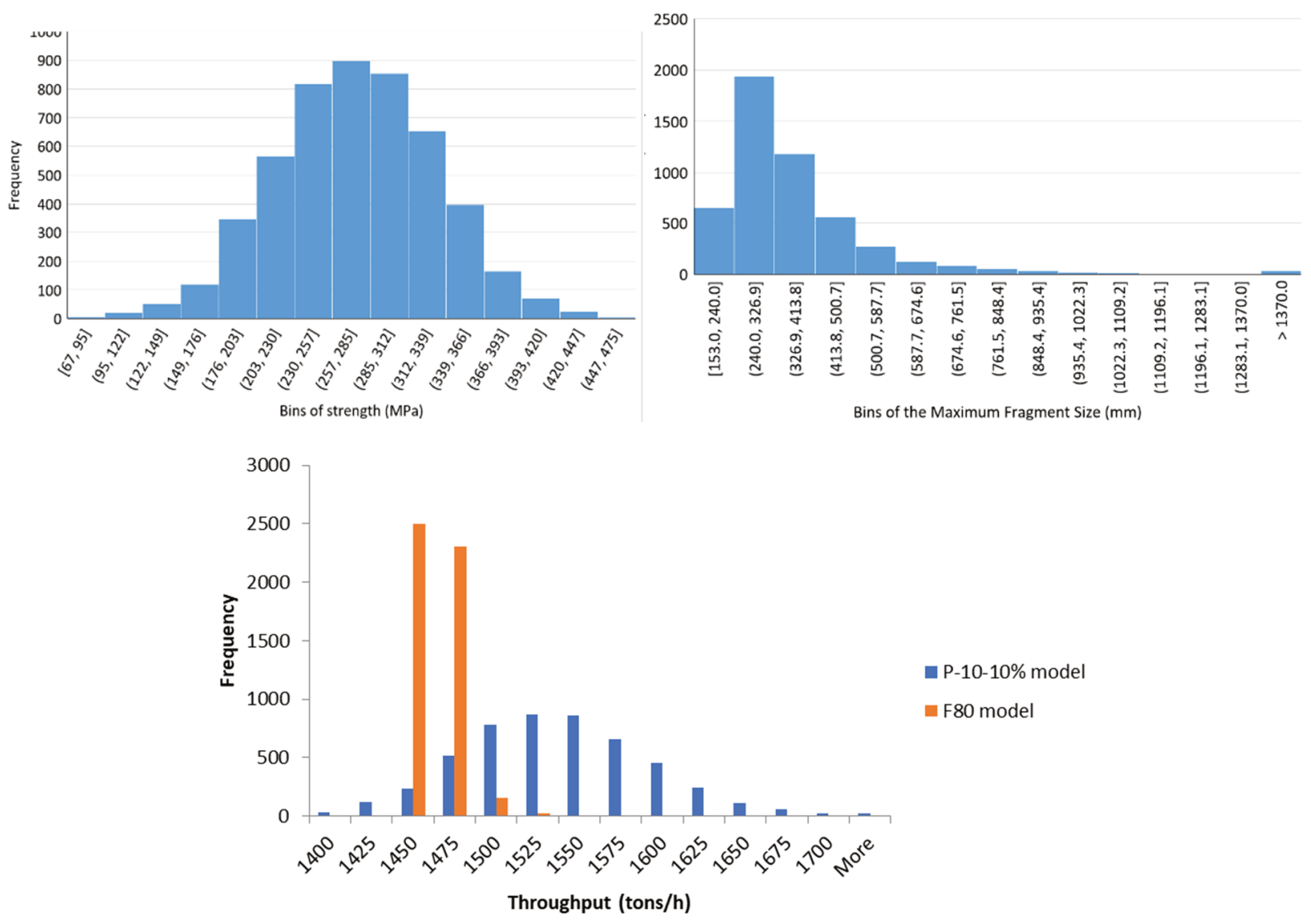

Figure 20 Monte Carlo simulation of throughput for a range of strengths and maximum fragment size using $F_{80}$ model (Equation 7) and showing the effect of fines using Equation 10

Taking all of this together, how do we put together a blast design processes that is useful and practical? One option is a cookbook approach, as shown in Figure 21. By considering that the strength and the in situ block size are the controlling influences on the fragmentation of a given blast design, we can determine the effect of that blast design on the rock mass across the potential spectrum of strength and IBSD. This will identify the opportunities for improvement. In Figure 21, a standard ring blast with an $89 \mathrm{~mm}$ hole on $2 \mathrm{~m}$ burden and $2.5 \mathrm{~m}$ spacing is used to predict the fragmentation. Upper and lower bounds of strength (100 MPa and $280 \mathrm{MPa}$ ) and in situ fracture frequency (1 and 30) are used to identify the IBSD and the blasted fragmentation. When the rock is very strong and coarse, low fines are produced, suggesting the potential for increasing fines by reducing spacing and burden to produce a high energy blast. When the rock is weak and fine, the potential for mud rushes and grinding to become bottlenecks in the mine and plant, respectively, implies that a lower energy blast may be more suitable.

This suggests three main blast designs for all stopes. Additional problems illustrated by red circles can be designed out by exception. These include the prevalence of critical size if the rock mass is strong but fine and 
breaks out on the blocks and without intra-block fracture. Secondly, the potential for underbreak in the hard coarse material, if the stress state is high and toes are far apart, can be reduced by proper toe spacing (Jackson \& Sellers 2017). Finally, the question of overbreak is probably one of the most difficult. If the rock mass is fine it will cave naturally; if coarse, it will create flow problems. Perhaps this is a question of stope shape rather than blast design.
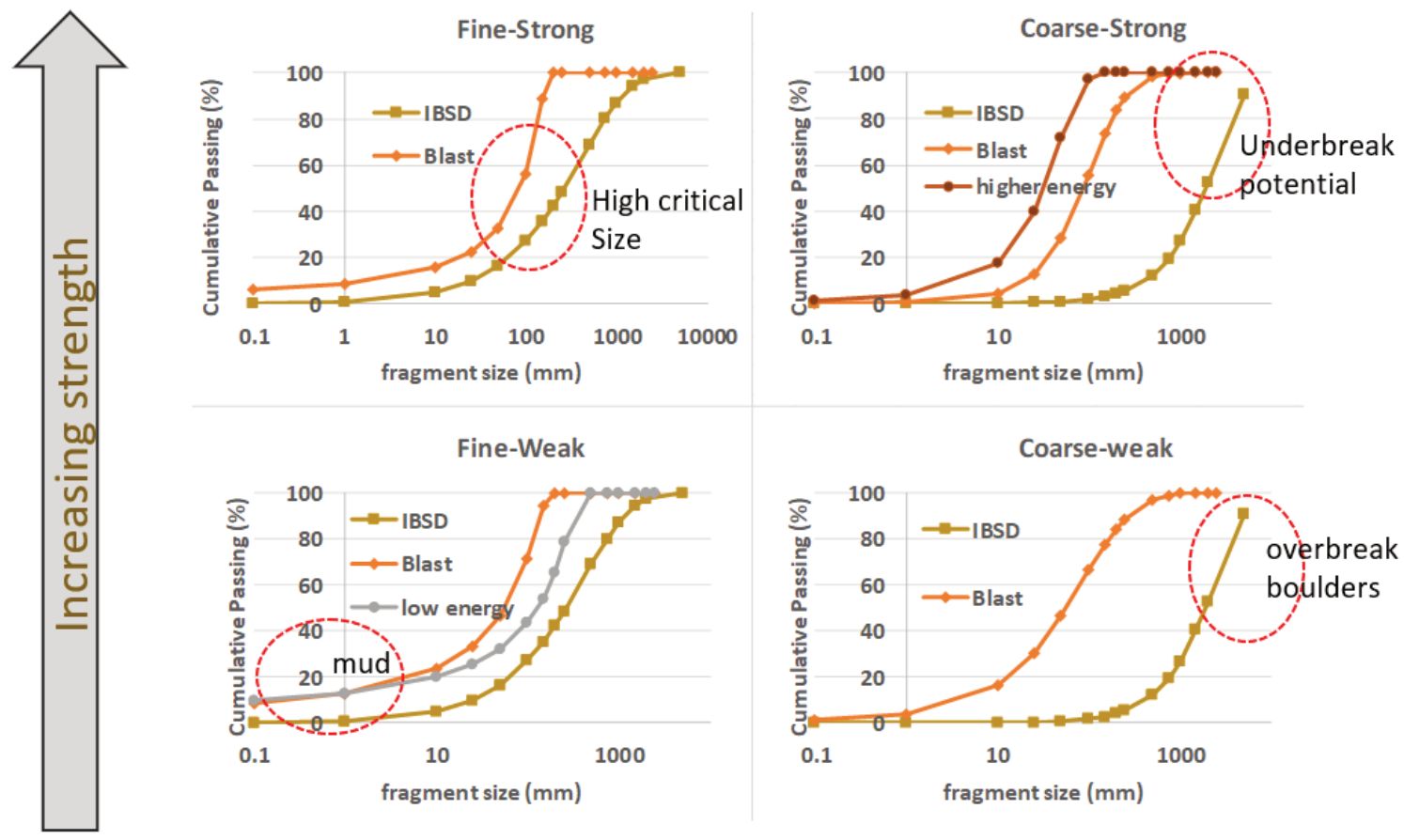

\section{Increasing IBSD}

Figure 21 Cookbook approach using data fusion from in situ block sizes

\section{The low energy, low emission, automated future mine}

As discussed in the introduction, worker safety, risk management, legal compliance, consideration of natural or man-made site conditions, and social responsibility are required for ESG performance and disclosure. New approaches need to be considered to transform existing and future operations to manage the requirements of lower energy, low carbon footprint, low mine footprint, reduced tailings hazards, and safer mining conditions through automation. The need to blast, extract, and transport the rock from its original place to a surface-located processing plant for further beneficiation requires large operating costs to extract ore, loading, and hauling to the surface. As mining depths increase and ore grades reduce, conventional mining methods become less profitable and, in some cases, uneconomic. Additionally, despite the potential for mine-to-mill improvements, more and more energy is consumed by comminution equipment. Comminution of $\mathrm{Au}$ and $\mathrm{Cu}$ ores requires $0.2 \%$ global and $1.3 \%$ Australian electricity and $36 \%$ of the energy used in mining energy is for comminution (Ballantyne \& Powell 2014). The largest potential for energy reduction is through preconcentration strategies (Ballantyne \& Powell 2014), implying selective mining to remove waste at an early stage, pre-crushing, and different plant configurations to improve throughput and reduce energy especially for the 'extreme' ore becoming more prevalent as ore bodies get increasingly harder, more abrasive, and lower in grade (Putland 2019). Future KPIs for mines will include measures such as $\mathrm{CO}_{2}$ per unit metal, energy per unit metal, and reduction in diesel particulate in the air.

Recently, Mining3 presented a novel idea of in-place mining (IPM) to minimise the rock movement by recovering the ore content in place (Mining3 2020). One approach is traditional in situ leachings (ISL) using 
recovery from drill hole works where the geometallurgy of the ore is suitable and the rock is permeable. Where the rock is hard, in-mine recovery is proposed where modified traditional underground mining methods are used to mine without extracting the broken rock (Figure 22). High energy blasting creates the fragmentation and the operation becomes a series of dump leach reactors in sealed chambers with modern, improved chemical/biological based methods being employed to recover the valuable mineral. The methods require updated blasting practices and mine sequence optimisation (Mousavi \& Sellers 2019). Alternatively, for a more automated, remote operational approach, the inline recovery (ILR) concept incorporates selective mining and ore upgrading in modular underground sizing and processing plants, such that only concentrated material is transported to the processing facility, significantly reducing the material movement to the surface.

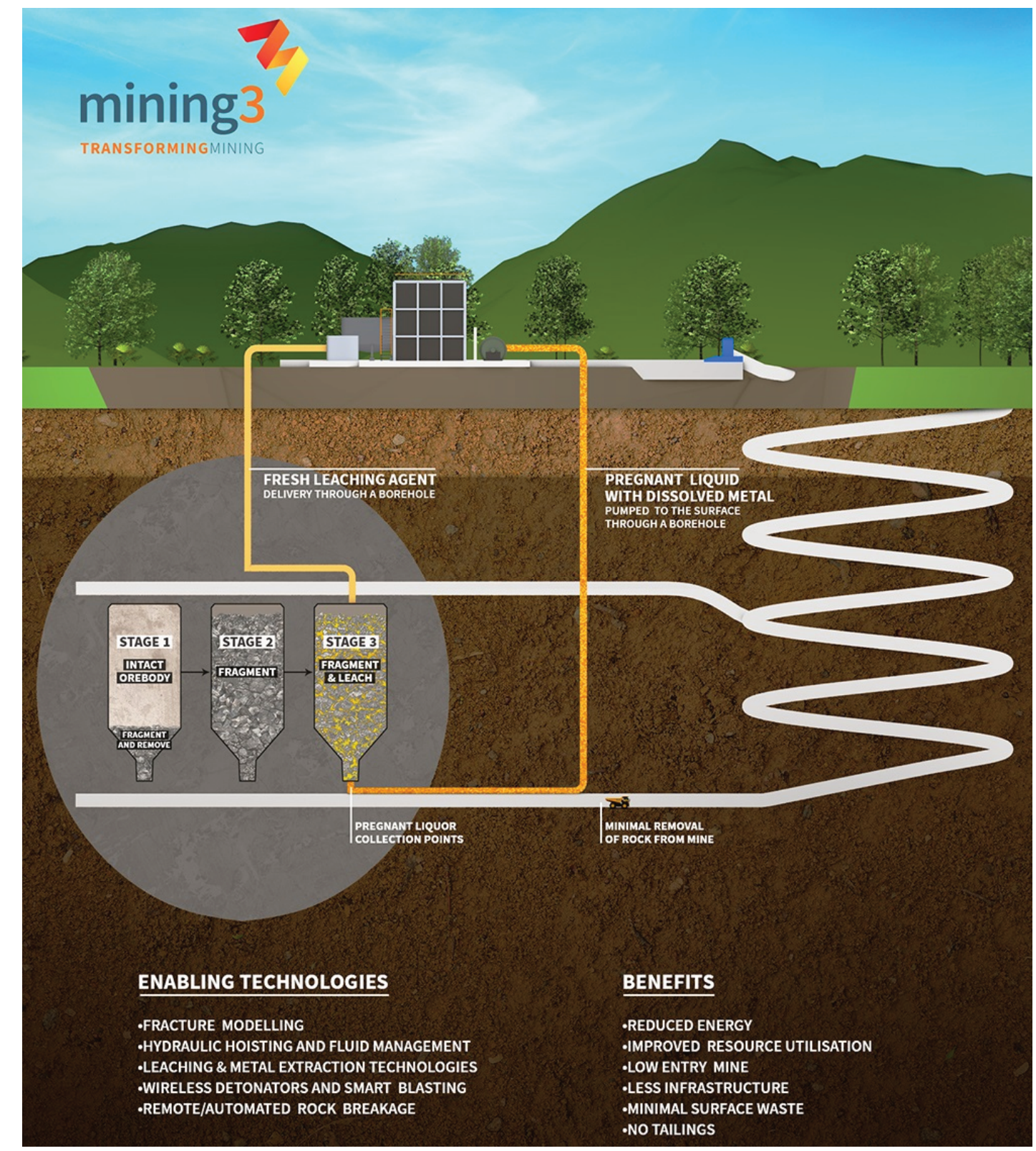

Figure 22 Schematic of in-mine recovery method (Mining3 2020)

Environmental concerns are raised about nitrates in the groundwater (Degnan et al. 2016). Poor detonation can lead to nitrate traces that are pumped out of the mine or washed off waste piles. Solutions include a new formulation of ammonium nitrate explosives protected in plastic sleeves (Teck 2020) and hydrogen peroxide-based explosives (Mining3 2020). 
Enabling safe operations managed by professionals in remote offices and transforming jobs for the future is the aim of mining automation. Automation requires strategic, mine design, and operational changes (Resolute 2019), multiple loT sensor platforms (Sennersten et al. 2015), and new frameworks for working with data by linking spatial information to design and management processes for decision support (Lindley et al. 2015).

The automation of blasting is lagging the other underground mining processes. For example, the Syama sublevel cave operation in Mali is currently one of the most advanced automation implementations with autonomous drilling, loading, haulage, dumping, and truck navigation (Resolute 2019) and yet not autonomous blasting. The first steps have been taken with the automation of the detection of blastholes, teleoperated arm pose control, automatic arm poses control, and human-in-the-loop visual servo control for charging blastholes in underground mining (Bonchis et al. 2014). Recently, an explosives company and original equipment manufacturer have announced a partnership to provide tele-remote blasthole charging in 2020 (Haselgrove 2019). Also, the Robominer robot that remotely primes and loads a blasthole, working together with an automised and teleoperated mobile manufacturing truck that can manufacture 20 tonnes of explosives has made the first fully remote operated blast in 2019 and is operating in a copper mine in the north of Chile (MiNE 2020).

\section{Conclusions}

Value addition in underground mining is much more complex than in surface mines. There are more methods and constraints to consider so the relationship between fragmentation and mill performance is not the only driving factor. Excessively high energy blasting creates damage to the rock mass through the fines produced to improve throughput. On the other hand, if the broken rock is too fine it may create mud rushes. The converse of insufficient energy leaves valuable ore remaining that requires additional cost to extract or produces boulders that create blockages since underground transport along with single-lane declines and up hoists after crushing provide constraints that are not manifested in surface mines. Thus, the blast designer must balance the rock mass and the rock strength, as well as in situ and mining-induced stresses, to create the most valuable blast outcomes.

Blast design approaches have been briefly reviewed and suggest that there is still work to be done. Simple, analytical models struggle with the complexity of ring design and the variability of the rock mass. Small-scale models produce indicative results though not design inputs. Numerical tools are still in a formative stage. Practical outcomes are required for improving value creation in underground mines and so the paper investigates how the rock mass properties should be selected for fragmentation analyses. The correct calculation of in situ block size is important. Rock strength has different meanings to geotechnical, blasting, and process engineers, and the differences are explained briefly. The higher range of rock strengths, i.e. $95 \%$ percentile, from geotechnical tests should be used for blast design because of the close interaction of the detonation with the local rock at the scale of the borehole. In situ and mining-induced stresses should be considered and further research is required for understanding the relationship between these stresses and fragmentation outcomes. A simple example highlights how underbreak and overbreak can be created by concentration and shielding of stresses through the full 3D dynamics of the excavation should be considered when numerical techniques are practical.

Data fusion of the various design tools and rock mass properties in 3D is vital for good blast performance. The cumulative effect of stress calibrated rock mass properties within, and outside, the potential stope boundaries need to be considered. Tools such as autonomous drones will drive huge improvements in blast design when the complete picture of outcomes can be related to all inputs. The effect of the rock mass can be predicted ahead and applied in long-term planning to create additional value by reducing bottlenecks. An approach that considers a matric of rock strength versus structure can lead to a few typical designs with edge cases being treated as required.

Currently, improvements in worker safety, risk management, legal compliance, consideration of natural or man-made site conditions, and ESG performance can be created alongside the improved NPV of traditional 
mine-to-mill. Future KPIs for mines will include measures such as emissions per unit metal, energy per unit metal, and reduction in diesel particulates. New mining approaches are suggested to transform mining and increase the ESG performance by reducing haulage and comminution energy, reducing tailings, and reducing the nitrates in the water. Mine automation is gathering momentum though there are few examples of the automation of blast loading. This is a complex process that will require further work for a practical, long-term solution.

\section{Acknowledgment}

The miners from various sites considered here are acknowledged for their interest and hard work under difficult conditions. Contributions from a reviewer, Catalina Canales and Brayhan Salazar, as well as discussions with many Mining3, CSIRO colleagues, friends, and mining professionals are gratefully acknowledged. Special thanks to Professor Hong Liu and Dr Daisuke Fukuda for their rapid development of the 3D FEM/DEM ring blast model.

\section{References}

Abdel Haffez, GS 2012, 'Correlation between Bond work index and mechanical properties of some Saudi ores', Journal of Engineering Sciences, Assiut University, vol. 40, no. 4, pp. 1217-1231.

Adhikari, GR \& Gupta, RN 1986, 'Influence of natural blocks on rock fragmentation by blasting', International Journal of Mining and Geological Engineering, vol. 7, pp. 333-340.

Adhikari, GR \& Gupta, RN 1989, 'Influence of discontinuity structure on rock fragmentation by blasting', International Journal of Mining and Geological Engineering, vol. 7, pp. 239-248.

AECl 1980a, 'Ring Blasting: Design of Ring Patterns', Explosives Today - African Explosives and Chemical Industries, vol. 21 , no. 2.

AECl 1980b, 'Ring Blasting: Optimising Results', Explosives Today - African Explosives and Chemical Industries, vol. 22, no. 2.

Azarkovich, AE \& Pokrovskii, GI 1991, 'Prediction of the particle-size distribution in blast-filled dams', Hydrotechnical Construction, vol. 25, no. 3, pp. 120-130.

Ballantyne, GR \& Powell, MS 2014, 'Benchmarking comminution energy consumption for the processing of copper and gold ores', Minerals Engineering, vol. 65, pp. 109-114.

Bamford, T, Esmaeili, K \& Schoellig, AP 2016, 'A real-time analysis of rock fragmentation using UAV technology', Proceedings of the 6th International Conference on Computer Applications in the Minerals Industries, https://arxiv.org/ftp/arxiv/papers/1607/1607.04243.pdf

Beck, DA, Lilley, CR, Reusch, F, Levkovitch, V, Putzar, G \& Flatten, A 2013, 'A preliminary, calibrated scheme for estimating rock mass properties for non-linear, discontinuum models', Proceedings of the 3rd ISRM Symposium on Rock Mechanics (Sinorock 2013), International Society for Rock Mechanics, Lisbon.

Bedair, A 1996, Digital image analysis of rock fragmentation from blasting, PhD thesis, McGill University, Montreal.

BHP 2011, Appendix C: Description of the Proposed Expansion, https://www.bhp.com/-/media/bhp/regulatory-informationmedia/copper/olympic-dam/0000/supplementary-eis-appendices/appendix-c_description-of-the-proposed-expansion.pdf

Bonchis, A, Duff, E, Roberts, J \& Bosse, M 2014, 'Robotic Explosive Charging in Mining and Construction Applications', IEEE Transactions on Automation Science and Engineering, vol. 11, pp. 245-250.

Bond, FC 1952, 'Third theory of comminution', Mining Engineering, vol. 4, pp. 484-494.

Bond, FC \& Whitney, BB 1959, 'The Work Index In Blasting', Proceedings of the 3rd U.S. Symposium on Rock Mechanics, American Rock Mechanics Association, Golden.

Brady, BHG 2004, Rock mechanics: for underground mining, Springer, Dordrecht.

Braithwaite, M 2012, 'Ideal detonation reaction concepts for blasting engineers', in B Mohanty \& VK Singh (eds), Proceedings of the 10th International Symposium on Rock Fragmentation by Blasting (FRAGBLAST 10), Taylor \& Francis, Milton Park, pp. 3-9.

Campbell, A \& Thurley, M 2017, 'Application of laser scanning to measure fragmentation in underground mines', Mining Technology, vol. 126, no. 4, pp. 240-247.

Casali, A 1990, 'Primary crusher optimal feed commanding the blast patterns in a quarry', Minerals Engineering, vol. 3, no. 5, pp. 517-523.

Chertkov, VY 1985, 'Chip/Fragment development during multiple crack formation in a brittle rock', Journal of Mining Science (Soviet Mining), vol. 21, no. 6, pp. 489-495.

Chung, SH \& Noy, MJ 1996, 'Experience in fragmentation control', in JA Franklin \& T Katsabanis (eds), Proceedings of the 5th International Symposium of Rock Fragmentation by Blasting (FragBlast) - Workshop on the Measurement of Blast Fragmentation, 1996, Montreal, Quebec, Canada, Balkema, Rotterdam, pp. 247-252.

Cunningham, C 1983, 'The Kuz-Ram model for prediction of fragmentation from blasting', in R Holmberg \& A Rustan (eds), Proceedings of the First International Symposium on Rock Fragmentation by Blasting, Luleå University of Technology, Luleå, pp. 439-453. 
Cunningham, C, Sellers, EJ \& Szendrei, T 2007, 'Cavity expansion energy applied to rock blasting', Proceedings of the Conference of the Fourth European Federation of Explosive Engineers (EFEE), European Federation of Explosives Engineers, Vienna, pp. 27-38.

Degnan, JR, Böhlke, JK, Pelham, K, Langlais, DM \& Walsh, GJ 2016, 'Identification of groundwater nitrate contamination from explosives used in road construction: isotopic, chemical, and hydrologic evidence', Environmental Science \& Technology, vol. 50, no. 2, pp. 593-603.

Deniz, V \& Ozdag, H 2003, 'A new approach to Bond grindability and work index: dynamic elastic parameters', Minerals Engineering, vol. 16, no. 3, pp. 211-217.

Devgan, A 1992, Analysis of rock fragmentation using digital image processing, PhD thesis, The University of Arizona, Tucson.

Ebbels, AM 2016, 'Optimising Underground Mining Strategies', Proceedings of the Project Evaluation 2016, The Australasian Institute of Mining and Metallurgy, Melbourne, pp. 60-65.

Elmouttie, M \& Poropat, G 2012, 'A method to estimate in situ block size distribution', Rock Mechanics and Rock Engineering, vol. 45, no. 3, pp. 401-407.

Etchells, SJ, Sellers, EJ \& Furtney, J 2013, 'Understanding the blast damage mechanisms in slopes using observations and numerical modelling', in PM Dight (ed.), Proceedings of the 2013 International Symposium on Slope Stability in Open Pit Mining and Civil Engineering, Australian Centre for Geomechanics, Perth, pp. 1359-1372.

Fatemi, A, Glaum, M \& Kaiser, S 2018, 'ESG performance and firm value: The moderating role of disclosure', Global Finance Journal, vol. 38, pp. 45-64.

Fava, L, Maybee, B \& Millar, D 2012, 'Decision support for an underground gold mining operation - a case study using the schedule optimisation tool', in A Pratt (ed.), Proceedings of the Project Evaluation 2012, The Australasian Institute of Mining and Metallurgy, Melbourne, pp. 41-48.

Fekete, S 2010, Geotechnical applications of LiDAR for geomechanical characterisation in drill and blast tunnels and representative 3dimensional discontinuum modelling, MSc thesis, Queen's University, Kingston.

Fekete, S \& Diederichs, M 2013, 'Integration of three-dimensional laser scanning with discontinuum modelling for stability analysis of tunnels in blocky rockmasses', International Journal of Rock Mechanics and Mining Sciences, vol. 57, pp. 11-23.

Fekete, S, Diederichs, M \& Lato, M 2010, 'Geotechnical and operational applications for 3-dimensional laser scanning in drill and blast tunnels', Tunnelling and Underground Space Technology, vol. 25, no. 5, pp. 614-628.

Fowler, MJ \& Weir, FM 2008, 'The Use of Borehole Breakout for Geotechnical Investigation of an Open Pit Mine', in Y Potvin \& R Jeffrey (eds), Proceedings of the First Southern Hemisphere International Rock Mechanics Symposium, Australian Centre for Geomechanics, Perth, pp. 541-550.

Franklin, JA, Ibarra, JA \& Maerz, NH 1989, 'Blast overbreak measurement by light sectioning', International Journal of Mining and Geological Engineering, vol. 7, pp. 323-331.

Franklin, JA, Maerz, NH \& Bennett, CP 1988, 'Rock mass characterization using photoanalysis', International Journal of Mining and Geological Engineering, vol. 6, no. 2, pp. 97-112.

Fukuda, D, Mohammadnejad, M, Liu, H, Zhang, Q, Zhao, J, Dehkhoda, S...\& Fujii, Y 2020, 'Development of a 3D hybrid finite-discrete element simulator based on GPGPU-Parallelized computation for modelling rock fracturing under quasi-static and dynamic loading conditions', Rock Mechanics and Rock Engineering, vol. 53, no. 3, pp. 1079-1112.

Furtney, J, Sellers, E \& Onederra, I 2012, 'Simple models for gas flow and burden movement during blasting', Proceedings of the 38th Annual Conference on Explosives and Blasting Technique, International Society of Explosive Engineers Inc., Nashville.

Furtney, JK, Andrieux, P \& Hall, AK 2016, 'Applications for Numerical Modeling of Blast Induced Rock Fracture', Proceedings of the 50th U.S. Rock Mechanics/Geomechanics Symposium, American Rock Mechanics Association, Alexandria.

Gaunt, J, Symonds, D, McNamara, G, Adiyansyah, B, Kennelly, L, EJ Sellers \& Kanchibotla, SS 2015, 'Optimisation of Drill and Blast for Mill Throughput Improvement at Ban Houayxai Mine', Proceedings of the 11th International Symposium on Rock Fragmentation by Blasting, The Australasian Institute of Mining and Metallurgy, Melbourne, pp. 307-314.

Germain, P \& Hadjigeorgiou, J 1997, 'Influence of stope geometry and blasting patterns on recorded overbreak', International Journal of Rock Mechanics and Mining Sciences, vol. 34, no. 3-4, pp. 115e1-115e12.

Ghosh, A \& Daemen, JJ 1993, 'Fractal characteristics of rock discontinuities', Engineering Geology, vol. 34, no. 1-2, pp. 1-9.

Goldratt, EM 1984, The Goal, North River Press, Great Barrington.

Grasedieck, AJ 2006, Die Natürliche Bruchcharakteristik (NBC) von Gesteinen in der Sprengtechnik (The natural breakage characteristics of rocks in rock blasting) (in German)', PhD thesis, University of Leoben, Leoben.

Guido, S, Grenon, M \& Germain, P 2017, 'Stope performance assessment at the Goldcorp Eleonore mine using bivariate analysis', Proceedings of AfriRock-Rock Mechanics for Africa, International Society for Rock Mechanics and Rock Engineering, Lisbon.

Gustafsson, R 1973, Swedish blasting technique, SPI and ABA Publishing Co., Gothenburg.

Hadjigeorgiou, J \& Stacey, TR 2013, 'The absence of strategy in orepass planning, design, and management', Journal of the Southern African Institute of Mining and Metallurgy, vol. 113, no. 10, pp. 795-801.

Hamoudeh, Y 2013, New future ring layout with parallel boreholes: results from small-scale blasting tests, Luleå University of Technology, Luleå.

Hamrin, H 2001, 'Hamrin, Hans Underground Mining Methods and Applications', in WA Hustrulid \& RL Bullock (eds), Proceedings of Underground Mining Methods - Engineering Fundamentals and International Case Studies, Society of Mining, Metallurgy and Exploration, Inc., Englewood.

Han, H, Fukuda, D, Liu, H, Salmi, EF, Sellers, E, Liu, T \& Chan, A 2020, 'Combined finite-discrete element modelling of rock fracture and fragmentation induced by contour blasting during tunnelling with high horizontal in-situ stress', International Journal of Rock Mechanics and Mining Sciences, vol. 127, pp. 104214. 
Hardy, A, Ryan, T \& Kemeny, J 1997, 'Block size distribution of in situ rock masses using digital image processing of drill core', International Journal of Rock Mechanics and Mining Sciences, vol. 34, no. 2, pp. 303-307.

Hardy, AJ 1993, Fragment size distribution of in situ rock masses from drill core, PhD thesis, The University of Arizona, Tuscon.

Haselgrove, S 2019, 'Orica, Epiroc to deliver automated blasting by 2020', Australian Mining, https://www.australianmining.com.au/news/orica-epiroc-to-deliver-automated-blasting-by-2020/

Holmberg, R, Hustrulid, WA \& Cunningham, C 2001, 'Blast design for underground mining applications', in WA Hustrulid \& RL Bullock (eds), Proceedings of Underground Mining Methods - Engineering Fundamentals and International Case Studies, Society of Mining, Metallurgy and Exploration, Inc., Englewood.

Hunter, G, McDermott, C, Miles, N, Singh, A \& Scoble, M 1990, 'A review of image analysis techniques for measuring blast fragmentation', Mining Science and Technology, vol. 11, no. 1, pp. 19-36.

Hustrulid, W \& Kvapil, R 2008, 'Sublevel caving - past and future', in HK Schunnesson \& E Nordlund (eds), Proceedings of the 5th International Conference and Exhibition on Mass Mining, Luleå University of Technology, Luleå, pp. 107-132.

Hustrulid, WA \& Bullock, RL 2001, Underground mining methods: Engineering fundamentals and international case studies, Society for Mining, Metallurgy, and Exploration, Littleton.

lqbal, H 2013, A new concept for timing double ring blasts: results from small-scale blasting tests, PhD thesis, Luleå University of Technology, Luleå.

Jackson, J \& Sellers, E 2017, 'Blasting related indices as the key to underground blasting improvements in a challenging rock mass', Proceedings 13th AusIMM Underground Operators' Conference, The Australasian Institute of Mining and Metallurgy, Melbourne, pp 23-32.

Jian, X, Elmouttie, M, Zhou, B \& Dean, P 2018, 'A novel 3D visualisation method for stochastic structural data with geophysical data for mining applications', Proceedings of the 2nd International Discrete Fracture Network Engineering Conference, American Rock Mechanics Association, Alexandria.

Jimeno, CL, Jimeno, EL \& Carcedo, FJA 1995, Drilling and blasting of rock, AA Balkema, Rotterdam.

Jones, E, Sofonia, J, Canales, C, Hrabar, S \& Kendoul, F 2020, 'Applications for the Hovermap autonomous drone system in underground mining operations', Journal of the Southern African Institute of Mining and Metallurgy, vol. 120, pp. 49-56.

Kanchibotla, S, Morrell, S, Valery, W \& O'Loughlin, P 1998, 'Exploring the effect of blast design on SAG mill throughput at KCGM', Proceedings of the Mine to Mill Conference, Australasian Institute of Mining and Metallurgy, Melbourne, pp. 153-158.

Katsabanis, PD 2020, 'Analysis of the effects of blasting on comminution using experimental results and numerical modelling', Rock Mechanics and Rock Engineering, pp. 1-17.

Katsabanis, PD, Gregersen, S, Kunzel, G, Pollanen, M, Pelley, C \& Kelebek, S 2005, 'Effects of blasting on damage and grindability of impacted rock', CIM Bulletin, pp. 51-57.

Kemeny, J, Donovan, J \& Silva, CR 2006, 'Application of groundbased LiDAR for preblast rock mass characterization', in C Orlandi \& IM Castro (eds), Proceedings of the 8th International Symposium on Rock Fragmentation by Blasting (FragBlast), Taylor \& Francis, Milton Park, pp. 50-54.

Kemeny, J, Mofya, E, Kaunda, R \& Lever, P 2002, 'Improvements in blast fragmentation models using digital image processing', Fragblast, vol. 6, no. 3-4, pp. 311-320.

Kemeny, JM 1994, 'Practical technique for determining the size distribution of blasted benches, waste dumps and heap leach sites', Mining Engineering, vol. 46, no. 11, pp. 1281-1284.

Kemeny, JM, Devgan, A, Hagaman, RM \& Wu, X 1993, 'Analysis of rock fragmentation using digital image processing', Journal of Geotechnical Engineering, vol. 119, no. 7, pp. 1144-1160.

Kluckner, P, Söllner, P, Schubert, W \& Pötsch, M 2015, 'Estimation of the in situ block size in jointed rock masses using three-dimensional block simulations and discontinuity measurements', in F Hassani (ed.), Proceedings of the 13th ISRM International Congress of Rock Mechanics, 2015, International Society for Rock Mechanics, Lisbon.

Kuznetsov, VM 1973, 'The mean diameter of the fragments formed by blasting rock', Soviet Mining, vol. 9, no. 2, pp. 144-148.

Langefors, U \& Kihlstrom, B 1973, The Modern Technique of Rock Blasting, John Wiley \& Sons, New York.

Latham, J-P, Kemeny, J, Maerz, N, Noy, M, Schleifer, J \& Tose, S 2003, 'A blind comparison between results of four image analysis systems using a photo-library of piles of sieved fragments', Fragblast, vol. 7, no. 2, pp. 105-132.

Lato, MJ \& Vöge, M 2012, 'Automated mapping of rock discontinuities in 3D lidar and photogrammetry models', International journal of rock mechanics and mining sciences (1997), vol. 54, pp. 150-158.

Lindley, CA, Sennersten, C, Davie, A, Goldstein, O, Lyu, R, Grace, A...\& Camargo, LDM 2015, 'A multilayer 3D index tool for recursive block models supporting terrestrial and extraterrestrial mine planning', Proceedings of the Third International Future Mining Conference, The Australasian Institute of Mining and Metallurgy, Melbourne, pp 289-296.

Lith, A, Kuchta, M \& Quinteiro, C 2004, 'Prediction of fragmentation for ring blasting in large-scale sublevel caving', Mine Planning and Equipment Selection 2004: Proceedings of the 13th International Symposium on Mine Planning and Equipment Selection, CRC Press/Balkema, London.

Little, TN \& Lovitt, MB 2018, 'Role of blasting in assisting with value based ore control in underground mines', in H Schunnesson \& D Johansson (eds), Proceedings of the 12th International Symposium on Rock Fragmentation by Blasting (FragBlast), Luleå University of Technology, Luleå, pp. 223-236.

Liu, Q 2006, 'Modification of the Kuz-Ram model for underground hard rock mines', Proceedings of the 8th International Symposium on Rock Fragmentation and Blasting (Fragblast 8), Taylor \& Francis, Milton Park, pp. 7-11.

Lownds, CM 1986, 'The strength of explosives', in JP Deetlefs (ed.), The Planning and Operation of Open-Pit and Strip Mines, Southern African Institute of Mining and Metallurgy, Johannesburg, pp. 151-159. 
Lu, P \& Latham, JP 1996, 'In-situ block size distribution prediction with special reference to discontinuities with fractal spacing distributions', in G Barla (ed.), Proceedings of EUROCK 96, International Society for Rock Mechanics and Rock Engineering, Lisbon, pp. 311-318.

Lu, W, Leng, Z, Chen, M, Yan, P \& Hu, Y 2016, 'A modified model to calculate the size of the crushed zone around a blast-hole', Journal of the Southern African Institute of Mining and Metallurgy, vol. 116, no. 5, pp. 412-422.

Maerz, NH, Palangio, TC \& Franklin, JA 1996a, 'WipFrag image based granulometry system', Proceedings of the FRAGBLAST 5 Workshop on Measurement of Blast Fragmentation, International Society for Rock Mechanics, Lisbon, pp. 91-99.

Maerz, NH, Ibarra, JA \& Franklin, JA 1996b, 'Overbreak and underbreak in underground openings Part 1: measurement using the light sectioning method and digital image processing', Geotechnical and Geological Engineering, vol. 14, pp. 307-323.

McKay, N, Vann, J, Ware, W, Morley, C \& Hodkiewicz, P 2016, 'Strategic and Tactical Geometallurgy - a Systematic Process to Add and Sustain Resource Value', Proceedings of the Third AusIMM International Geometallurgy Conference, The Australasian Institute of Mining and Metallurgy, Melbourne, pp. 29-36.

McKee, DJ 2013, Understanding Mine to Mill, The Cooperative Research Centre for Optimising Resource Extraction (CRC ORE), University of Queensland, St Lucia.

McKee, DJ, Chitombo, GP \& Morrell, S 1995, 'The relationship between fragmentation in mining and comminution circuit throughput', Minerals Engineering, vol. 8, no. 11, pp. 1265-1274.

Meyer, G, Larking, A, Jeffrey, R \& Bunger, A 2010, 'Olympic Dam EGS Project', Proceedings of the World Geothermal Congress, International Geothermal Association, Bonn, pp. 1-6.

Miller, J, Fouet, T, Mccuaig, C, Widdup, H \& Hodgkison, J 2004, 'A three-dimensional structural interpretation of the Olympic Dam deposit-implications for mine planning and exploration', Proceedings of the Pacrim 2004 Congress, Australasian Institute of Mining and Metallurgy, Melbourne, pp. 417-426.

MiNE 2020, Marco Ruis Q\&A: robotics and safety inthe mining industry, https://mine.nridigital.com/mine_oct20/enaex_robotics. Mining3 2020, Alternative explosives -Blasting without toxic fumes, https://www.mining3.com/research/alternative-explosives/.

Morrell, S 2004, 'Predicting the specific energy of autogenous and semi-autogenous mills from small diameter drill core samples', Minerals Engineering, vol. 17, no. 3, pp. 447-451.

Morrell, S 2006, 'Design of AG/SAG mill circuits using the SMC Test', Proceedings of the International Autogenous and Semi-Autogenous Grinding Technology, Canadian Institute of Mining, Metallurgy and Petroleum, Montreal, pp. IV-279-IV-298.

Morrell, S 2009, 'Predicting the overall specific energy requirement of crushing, high pressure grinding roll and tumbling mill circuits', Minerals Engineering, vol. 22, no. 6, pp. 544-549.

Morrell, S 2011, 'The appropriateness of the transfer size in AG and SAG mill circuit design', Proceedings of the Fifth International Conference on Autogenous and Semiautogenous Grinding Technology, Canadian Institute of Mining, Metallurgy and Petroleum, Montreal, pp. 25-28.

Morrison, R \& Richardson, J 2002, 'JKSimMet: A simulator for analysis, optimisation and design of comminution circuits', Proceedings of the Symposiumof Mineral processing plant design, practice, and control, Society for Mining, Metallurgy, and Exploration, Englewood, pp. 442-460.

Mousavi, A \& Sellers, E 2019, 'Optimisation of production planning for an innovative hybrid underground mining method', Resources Policy, vol. 62, pp. 184-192.

Murr, D, Workman, L, Eloranta, J \& Katsabanis, T 2015, 'Blasting influence on comminution', Proceedings of the 6th International Semi-Autogenous Grinding and High Pressure Grinding Roll Technology Conference, University of British Columbia, Vancouver, pp. 1-21.

Olofsson, SO 1990, Applied explosive techniology for construction and mining, 2nd edn, Applex, Arla.

Onederra, I \& Chitombo, G 2007, 'Design methodology for underground ring blasting', Mining Technology, vol. 116, no. 4, pp. 180-195.

Ouchterlony, F 2005a, 'The Swebrec ${ }^{\odot}$ function: linking fragmentation by blasting and crushing', Mining Technology: Transactions of the Institutions of Mining and Metallurgy: Section A, vol. 114, pp. A29-A44.

Ouchterlony, F 2005b, 'What does the fragment size distribution of blasted rock look like?', in R Holmberg (ed.), Proceedings of the Third European Federation of Explosives Engineers (EFEE) World Conference on Explosives and Blasting, European Federation of Explosives Engineers, Vienna, pp. 189-199.

Ouchterlony, F 2010a, 'A common form for fragment size distributions from blasting and a derivation of a generalized Kuznetsov's x50-equation', in JA Sanchidrián (ed.), Proceedings of the 10th Conference on Rock Fragmentation by Blasting, Taylor \& Francis, Milton Park, pp. 199-208.

Ouchterlony, F 2010b, 'Fragmentation characterization; the Swebrec function and its use in blast engineering', in JA Sanchidrián (ed.), Proceedings of the 9th Conference on Rock Fragmentation by Blasting (Fragblast 9), Taylor \& Francis, Milton Park, pp. 3-22.

Ouchterlony, F, Olsson, M, Nyberg, U, Andersson, P \& Gustavsson, L 2006, 'Constructing the fragment size distribution of a bench blasting round, using the new Swebrec function', Proceedings of the 8th Conference of Rock Fragmentation by Blasting (Fragblast 8), Taylor \& Francis, Milton Park, pp. 332-344.

Ouchterlony, F \& Sanchidrián, JA 2019, 'A review of development of better prediction equations for blast fragmentation', Rock Mechanics and Geotechnical Engineering, vol. 11, no. 5, pp. 1094-1109.

Ouchterlony, F, Sanchidrián, JA \& Moser, P 2017, 'Percentile fragment size predictions for blasted rock and the fragmentation-energy fan', Rock Mechanics and Rock Engineering, vol. 50, no. 4, pp. 751-779.

Palmström, A 2000, 'Block size and block size distribution', paper presented at workshop Reliablity of classification systems in association with GeoEng2000 Conference, pp. 1-12. 
Persson, P-A, Holmberg, R \& Lee, J 1993, Rock blasting and explosives engineering, CRC Press, Boca Raton.

Potvin, Y, Grant, D \& Mungur, G 2015, 'Towards a practical stope reconciliation process in large-scale bulk underground stoping operations, Olympic Dam, South Australia', CIM Journal, vol. 6, no. 2, pp. 102-110.

Potvin, Y, Grant, D, Mungur, G, Wesseloo, J \& Kim, Y 2016, 'Practical stope reconciliation in large-scale operations part 2 Olympic Dam South Australia', Proceedings of the 7th International Conference on Mass Mining, Australasian Institute of Mining and Metallurgy, Melbourne, pp. 501-509.

Powell, MS, Mainza, AN, Hilden, MH \& Yahyaei, M 2015, 'Full pre-crush to SAG mills-the case for changing this practice', Proceedings of the 6th International Semi-autogenous Grinding and High Pressure Grinding Roll Technology, Canadian Institute of Mining and Metallurgy, Vancouver.

Putland, BS, R. 2019, 'Hard rock - crush it or let it break itself', Proceedings of the 7th International Semi-Autogenous Grinding and High Pressure Grinding Roll Technology Conference, University of British Columbia, Vancouver.

Resolute 2019, 'Mine more gold. create more value', Diggers \& Dealers Mining Forum, https://clients3.weblink.com.au/ pdf/RSG/02130750.pdf

Riquelme, AJ, Abellán, A, Tomás, R \& Jaboyedoff, M 2014, 'A new approach for semi-automatic rock mass joints recognition from 3D point clouds', Computers \& Geosciences, vol. 68, pp. 38-52.

Rose, J, Grant, D \& O'Toole, D 2016, 'Orepass monitoring and management at Olympic Dam Mine', Proceedings Seventh International Conference and Exhibition on Mass Mining (MassMin 2016), Australasian Institute of Mining and Metallurgy, Melbourne, pp 609-616.

Rustan, A 1990, 'The importance of using joints to achieve scaled fragmentation in magnetite concrete used for sublevel caving blast models', Engineering Fracture Mechanics, vol. 35, no. 1-3, pp. 425-438.

Rustan, A 2012, 'The dynamics and fragmentation of blasted ore slices in scaled sublevel caving and slab models followed by accuracy analysis of the "Volume weight method" used for determination of ore content at loading', Proceedings of the 10th Symposium on Rock Fragmentation by Blasting, CRC Press, Milton Park, pp. 357-371.

Sainsbury, B, Sainsbury, D \& Vakili, A 2015, 'Discrete analysis of open stope stability', in Y Potvin (ed.), Proceedings of the International Seminar on Design Methods in Underground Mining, Australian Centre for Geomechanics, Perth, pp. 79-94.

Sanchidrián, J, Segarra, P \& López, L 2006, 'A practical procedure for the measurement of fragmentation by blasting by image analysis', Rock Mechanics and Rock Engineering, vol. 39, no. 4, pp. 359-382.

Sanchidrián, J, Segarra, P, Ouchterlony, F \& López, L 2009, 'On the accuracy of fragment size measurement by image analysis in combination with some distribution functions', Rock Mechanics and Rock Engineering, vol. 42, no. 1, pp. 95-116.

Sanchidrián, JA, Ouchterlony, F, Moser, P, Segarra, P \& López, LM 2012, 'Performance of some distributions to describe rock fragmentation data', International Journal of Rock Mechanics and Mining Sciences, vol. 53, pp. 18-31.

Sanchidrián, JA, Ouchterlony, F, Segarra, P \& Moser, P 2014, 'Size distribution functions for rock fragments', International Journal of Rock Mechanics and Mining Sciences, vol. 71, pp. 381-394.

Schleifer, J \& Tessier, B 1996, 'FRAGSCAN: A tool to measure fragmentation of blasted rock', in JA Franklin \& T Katsabanis (eds), Proceedings of the 5th International Symposium of Rock Fragmentation by Blasting (FragBlast) - Workshop on the Measurement of Blast Fragmentation, CRC Press, Milton Park, pp. 73-78.

Scott, A, Kanchibotla, S \& Morrell, S 1999, 'Blasting for mine to mill optimisation', Proceedings of Explo'99: a Conference On Rock Breaking, Australasian Institute of Mining and Metallurgy, Melbourne, pp. 3-8.

Scott, A, Morrell, S \& Clark, D 2002, 'Tracking and quantifying value from 'mine to mill' improvement', Proceedings of the Value Tracking Symposium, Australasian Institute of Mining and Metallurgy, Melbourne.

Scott, A \& Onederra, I 2015, 'Characterising the blasting properties of iron ore', Proceedings of the Iron Ore Conference, Australasian Institute of Mining and Metallurgy, Melbourne, pp. 481-490.

Sellers, E, Furtney, J, Onederra, I \& Chitombo, G 2012, 'Improved understanding of explosive-rock interactions using the hybrid stress blasting model', Journal of the Southern African Institute of Mining and Metallurgy, vol. 112, no. 8, pp. 721-728.

Sellers, E, Kotze, M, Dippenaar, L \& Ruest, M 2010, 'Large scale concrete cube blasts for the HSBM model', Proceedings of the 9th International Symposium on Rock Fragmentation by Blasting (Fragblast 9), Taylor \& Francis, Milton Park.

Sellers, EJ, Kennelly, L., Withers, B, Monro, K \& Reid, D 2018, 'Design and implementation improvements for wall control blasting in an anisotropic rock mass at the Phu Kham Copper-Gold Operation', in H Schunnesson \& D Johansson (eds), Proceedings of the 12th International Symposium on Rock Fragmentation by Blasting, Luleå University of Technology, Luleå.

Sennersten, C, Lindley, CA, Davie, A, Lyu, R, Grace, A, Evans, B,...Craig, J 2015, 'Unmanned Aerial Robots for Remotely Operated and Autonomous Surveying in Inaccessible Underground Mine Voids', Proceedings of the Third International Future Mining Conference, Australasian Institute of Mining and Metallurgy, Melbourne, pp. 101-108.

Shi, F \& Kojovic, T 2007, 'Validation of a model for impact breakage incorporating particle size effect', International Journal of Mineral Processing, vol. 82, no. 3, pp. 156-163.

Silva, M \& Casali, A 2015, 'Modelling SAG milling power and specific energy consumption including the feed percentage of intermediate size particles', Minerals Engineering, vol. 70, pp. 156-161.

Singh, A 1986, Photographic evaluation of blast fragmentation, PhD thesis, McGill University, Montreal.

Singh, SP \& O'Connor, PC 2007, 'Prediction and assessment of fragmentation during ring blasting', Proceedings of the Fourth European Federation of Explosives Engineers (EFEE) World Conference on Explosives and Blasting, European Federation of Explosives Engineers, Vienna, pp. 83-89.

Teck 2020, Helping to protect water quality with new blasting practices that reduce nitrate at the source, https://www.teck.com/news/stories/2020/ 
Thurley, M, Wimmer, M \& Nordqvist, A 2015, 'Blast fragmentation measurement based on 3D imaging in sublevel caving draw-points and LHD buckets at LKAB Kiruna', Proceedings of the 11th International Symposium on Rock Fragmentation by Blasting, The Australasian Institute of Mining and Metallurgy, Melbourne, pp. 763-774.

Török, J, Lévay, S, Szabó, B, Somfai, E, Wegner, S, Stannarius, R \& Börzsönyi, T 2017, 'Arching in three-dimensional clogging', Proceedings of Powders and Grains 2017 - 8th International Conference on Micromechanics on Granular Media, Curran Associates, Inc, Red Hook.

Tyupin, VN \& Anisimov, VN 2018, 'Effect of geological and geophysical characteristics of complex-structure ferruginous quartzite ore bodies on blasting and processing performance', Journal of Mining Science, vol. 54, no. 1, pp. 48-52.

Vatandoost, A 2010, Petrophysical characterization of comminution behaviour, PhD thesis, University of Tasmania, Hobart.

Villaescusa, E 1995, 'Sources of external dilution in underground sublevel and bench stoping', Proceedings of Explo'95, pp. 217-223.

Villaescusa, E 2014, Geotechnical design for sublevel open stoping, CRC Press, Boca Raton.

Wang, H, Latham, JP \& Poole, AB 1991, 'Predictions of block size distribution for quarrying', Quarterly Journal of Engineering Geology and Hydrogeology, vol. 24, no. 1, pp. 91-99.

Wang, L, Yamashita, S, Sugimoto, F, Pan, C \& Tan, G 2003, 'A methodology for predicting the in situ size and shape distribution of rock blocks', Rock Mechanics and Rock Engineering, vol. 36, no. 2, pp. 121-142.

White, DH 1977, Predicting fragmentation characteristics of a block caving orebody, PhD thesis, The University of Arizona, Tucson.

Widzyk-Capehart, E 1998, Digital image technology for fragmented material characterization, PhD thesis, Michigan Technology University, Houghton.

Wimmer, M 2012, Towards understanding breakage and flow in sublevel caving (SLC): Development of new measurement techniques and results from full-scale tests, $\mathrm{PhD}$ thesis, Luleå University of Technology, Luleå.

Wimmer, M, Ouchterlony, F \& Moser, P 2008, 'The fragment size distribution of Kiruna magnetite, from model-scale to run of the mine', in H Schunnesson \& E Nordlund (eds), Proceedings of the 5th International Conference and Exhibition on Mass Mining, Luleå University of Technology, Luleå, pp. 691-703.

Yi, C, Sjöberg, J \& Johansson, D 2017, 'Numerical modelling for blast-induced fragmentation in sublevel caving mines', Tunnelling and Underground Space Technology, vol. 68, pp. 167-173.

Zhang, ZX 2008, 'Impact of rock blasting on mining engineering', in H Schunnesson \& E Nordlund (eds), Proceedings of the 5th International Conference and Exhibition on Mass Mining, Luleå University of Technology, Luleå, pp. 671-680. 